\title{
Relative Importance of the Austral Summer and Autumn SAM in Modulating Southern Hemisphere Extratropical Autumn SST*
}

\author{
FEI ZHENG \\ State Key Laboratory of Numerical Modeling for Atmospheric Sciences, and Geophysical Fluid Dynamics, Institute \\ of Atmospheric Physics, Chinese Academy of Sciences, Beijing, China \\ JIANPING LI AND JUAN FENG \\ College of Global Change and Earth System Science, Beijing Normal University, and Joint Center for Global \\ Change Studies, Beijing, China \\ YANJIE LI \\ State Key Laboratory of Numerical Modeling for Atmospheric Sciences, and Geophysical Fluid Dynamics, Institute \\ of Atmospheric Physics, Chinese Academy of Sciences, Beijing, China \\ YANG LI \\ College of Atmospheric Science, Lanzhou University, Lanzhou, Gansu, and State Key Laboratory of Numerical \\ Modeling for Atmospheric Sciences, and Geophysical Fluid Dynamics, Institute of Atmospheric Physics, Chinese \\ Academy of Sciences, Beijing, China
}

(Manuscript received 3 March 2015, in final form 2 July 2015)

\begin{abstract}
Sea surface temperature (SST) variability in the extratropical Southern Hemisphere is mainly determined by physical processes at the air-sea interface associated with the Southern Hemisphere annular mode (SAM). Both the austral summer [December-February (DJF)] and autumn [March-May (MAM)] SAM can imprint their signals on southern extratropical MAM SST. Here three approaches are employed to determine the relative importance of the DJF and MAM SAM in modulating southern extratropical MAM SST: a simple lead-lag correlation without SST decomposition, a decomposition method based on linear regression, and a new approach named the persistent signal decomposition (PSD). The results show that the DJF SAM plays a more important role than the MAM SAM in driving MAM large-scale southern extratropical SST anomalies, implying that MAM SST anomalies caused by the preceding DJF SAM would not be largely perturbed by the MAM SAM, and thus the DJF SAM can be regarded as an effective predictor for the following season's climate. The PSD also provides an estimation of the contribution of atmospheric persistence and SST persistence toward cross-seasonal influence of the DJF SAM on MAM southern extratropical SST. The results show that this cross-seasonal influence is mainly caused by the SST persistence. The detection of the relative importance of the preceding and contemporaneous atmospheric signal in driving SSTA contributes to the understanding of air-sea interactions and helps to obtain better SST-based statistical predictions. The PSD has the potential to be employed in the North Atlantic and other extratropical oceans.
\end{abstract}

\footnotetext{
* Supplemental information related to this paper is available at the Journals Online website: http://dx.doi.org/10.1175/JCLI-D-150170.s1.

Corresponding author address: Dr. Jianping Li, College of Global Change and Earth System Science, Beijing Normal University, No. 19, XinJieKouWai St., HaiDian District, Beijing 100875, China. E-mail: ljp@bnu.edu.cn
}

\section{Introduction}

Sea surface temperature (SST) provides an important source of predictability in climate systems due to its signal persistence, which is usually greater than that of the atmospheric circulation because of the large heat capacity of the ocean (e.g., Frankignoul and Hasselmann 1977; Namias et al. 1988; Wang et al. 2000; Watanabe and Kimoto 2000; Deser et al. 2003; Pan 2005, 2007; Deser 
et al. 2010; Ding and Li 2011, 2012; Ciasto et al. 2011; Tokinaga et al. 2012). Therefore, SST is an important "linking bridge" for cross-seasonal connections and an important predictor in climate predictions.

In particular, the SST persistence is a foundation for the cross-seasonal influence of the December-February (DJF) Southern Hemisphere annular mode (SAM) on southern China March-May (MAM) precipitation (Zheng and Li 2012). The SAM is the dominant mode of atmospheric circulation in the southern extratropics (Gong and Wang 1999; Thompson and Wallace 2000; Thompson et al. 2000; Li and Wang 2003). A seasonal prediction model for southern China MAM precipitation has been developed based on the DJF SAM and employed successfully in statistical prediction ( $\mathrm{Li}$ et al. 2013a). The corresponding mechanism may be summarized as follows. The DJF SAM alters southern extratropical SST through both dynamical and thermodynamic processes (Watterson 2000; Cai and Watterson 2002; Lefebvre et al. 2004; Sen Gupta and England 2006; Wu et al. 2009a; Thompson et al. 2011; Zheng and Li 2012), and leads to a dipolelike SST anomaly (SSTA) pattern south of $30^{\circ} \mathrm{S}$. For brevity, this SAMinduced SSTA pattern is referred to as the Southern Hemisphere ocean dipole (SOD). The SAM-induced SOD persists to MAM due to SST persistence, influences the vertical motion over southern China through its modulation on zonal-mean meridional circulation via wave-mean flow interactions and corresponds to changes in the position of northwestern Pacific subtropical high, and thus leads to MAM precipitation anomalies over southern China (Zheng and Li 2012).

In short, the DJF SAM imprints its signal on MAM SST and provides a source of predictability for southern China MAM precipitation. However, as will be shown in section 3b, the MAM SAM may also influence MAM SST and lead to a similar SSTA pattern in the southern extratropics (see also Ciasto and Thompson 2008). Therefore, the MAM SST field in the southern extratropics contains both anomalies caused by the DJF and MAM SAM. The problem then is to estimate the relative importance of the DJF and MAM SAM in modulating the MAM SST. If the DJF SAM plays a dominant role in influencing MAM SST, the DJF SAM and associated SSTA can be regarded as effective predictors for the following season's climate. However, if the MAM SAM makes a larger contribution, the MAM SSTA caused by the DJF SAM may be modulated to a great extent by the MAM SAM, and thus the preceding season signals for seasonal prediction would be perturbed. Therefore, the aim of this study is to detect the relative contributions of the DJF and MAM SAM in driving MAM SSTA in the Southern Hemisphere extratropics.
One may imagine that the relative contributions of the DJF and MAM SAM-MAM SST could be found by directly calculating the correlation coefficients of MAM SST with the DJF and MAM SAM, respectively. Undoubtedly, this method is effective and concise in the absence of strong SST persistence, and is convenient for understanding the elementary features of the correlation between the SAM and SST. If we take the SST persistence into account and need to compare the role of the DJF and MAM SAM in regulating MAM SST, a comparison between this "direct" correlation of MAM SST with the DJF and MAM SAM may be not accurate enough. Although the direct correlation between the DJF SAM and MAM SST still reflects the "pure" linkage between them in view of their temporal leading relationship, the direct correlation between the MAM SAM and MAM SST may not reflect their real linkage, since the contemporaneous correlation is not equal to causality and the total MAM SST contains a persistent component caused by the DJF SAM (more details in sections $5 \mathrm{a}$ and $5 \mathrm{~b}$ ).

Combing statistics with physical process allows getting closer to causality. A more accurate understanding of the relative importance of the DJF and MAM SAM on MAM SST is facilitated by first figuring out the physical process through which the cross-seasonal influence of the DJF SAM on MAM SST occurs, and then by decomposing total MAM SST into persistent and nonpersistent components. One way to conduct SST decomposition has been used in studies exploring the influence of the North Atlantic Oscillation (NAO) on Northern Hemisphere extratropical SST. For example, Wu et al. (2009b) estimated June-August (JJA) SSTA generated by the MAM and JJA NAO, and found that the MAM NAO is more important than the JJA NAO in driving triple-like JJA SSTA in the North Atlantic. In their work, they make a simple decomposition of JJA SST using unary linear regression, in which the dependent variable is JJA SST and the independent variable is MAM SST. Therefore, JJA SST is decomposed to a persistent component derived from MAM SST and a nonpersistent component independent of MAM SST (see Pan 2005; also see sections $4 d$ and $5 b$ in the current manuscript).

However, the above SST decomposition method did not consider the role of air-sea interaction in the crossseasonal influence and cannot distinguish the persistent SST component related with one specific atmospheric factor (e.g., NAO or SAM) from the total persistent component. Therefore, we need to reconsider the physical process through which the cross-seasonal influence occurs under the framework of air-sea interactions, and to develop a new SST decomposition process for 
distinguishing the persistent SST component related with a special atmospheric factor, here the SAM.

The aim of this work is to explore the relative importance of the DJF and MAM SAM in influencing southern extratropical MAM SST and develop a new process for accurately understanding their relative contribution. Taking into consideration that the zonal symmetric component is dominated in the SAM signal, the focus of the present study is the large-scale zonal-mean southern extratropical SSTA. The remainder of this paper is organized as follows. In section 2, we introduce the data and basic statistical method. The direct correlation of the DJF and MAM SAM with contemporaneous SST and the cross-seasonal influence of the DJF SAM on MAM SST are analyzed in section 3 . In section 4 , we introduce three approaches used to detect the relative importance of the DJF and MAM SAM in influencing MAM SST, including a new SST decomposition approach named the persistent signal decomposition (PSD). In section 5, three approaches are employed to quantify the relative importance of the DJF and MAM SAM in modulating MAM SST. Finally, a discussion and the conclusions are presented in section 6 .

\section{Data and basic statistical methods}

\section{a. Data}

This study focuses on the austral summer (DJF) and the following austral autumn (MAM) seasons, and the analysis period is from $1978 / 79$ to $2011 / 12$. In most cases, the variables were converted to seasonal means prior to analysis. We use atmospheric circulation data from the National Centers for Environmental Prediction-National Center for Atmospheric Research (NCEP-NCAR) Reanalysis 1 , with a resolution of $2.5^{\circ} \times 2.5^{\circ}$. The main variables employed are horizontal wind velocity, vertical velocity, geopotential height, and sea level pressure. The SST dataset is the Hadley Centre Sea Ice and SST dataset (HadISST), with a resolution of $1.0^{\circ} \times 1.0^{\circ}$.

We quantify the effect of the SAM by using the SAM index (SAMI) defined by Nan and Li (2003), which is the difference in normalized monthly zonally averaged sea level pressure between $40^{\circ}$ and $70^{\circ} \mathrm{S}$. This definition is widely used in research on the SAM and its climatic impact (Nan et al. 2009; Wu et al. 2009a; Feng et al. 2010, 2013; Li and Li 2012).

The SAM-associated dipolelike SSTA pattern south of $30^{\circ} \mathrm{S}$, referred to as the SOD, is expressed in terms of an index defined as the difference in normalized SST between $40^{\circ}$ and $60^{\circ} \mathrm{S}$. We choose these two latitudes because the zonal-mean SSTs are strongest anticorrelated here. The positive (negative) phase of the SOD denotes warmer (cooler) SST in the southern middle latitudes and cooler (warmer) SST at high latitudes. In most areas north of $65^{\circ} \mathrm{S}$, the sea ice melts completely in the seasons of interest (December-May). Therefore, in the definition of the SOD index (SODI), it is reasonable to choose $40^{\circ}$ and $60^{\circ} \mathrm{S}$ and generally ignore the influence of sea ice.

The SAM, El Niño-Southern Oscillation (ENSO), and Southern Hemisphere extratropical SST are closely correlated in the austral warm seasons (e.g., Karoly 1989; Seager et al. 2003; Zhou and Yu 2004; Ciasto and Thompson 2008; Simpkins et al. 2014; Ciasto et al. 2015). To explore the linkage among the SAM, ENSO, and southern extratropical SST, the Niño-3.4 index is used to represent the ENSO variability. The Niño-3.4 index is defined as the regionally averaged SST over $5^{\circ} \mathrm{S}-5^{\circ} \mathrm{N}$, $170^{\circ}-120^{\circ} \mathrm{W}$.

\section{b. Basic statistical methods}

The linear regression analysis is the basis for the PSD. Standardized linear regression is adopted to explore linkage between the independent variables and the dependent variable. For two variables $\left(x_{1}\right.$ and $\left.x_{2}\right)$, the standardized binary regression equation is expressed as

$$
\hat{y}=b_{1} x_{1}+b_{2} x_{2},
$$

where $\hat{y}$ is the fitting of the dependent variable $y ; b_{1}$ and $b_{2}$ are the standardized partial regression coefficients.

Note that we use standardized variables $\left(x_{1}, x_{2}, y\right)$ to build the regression equation to remove the units of the predictors and the predictand. The standardized regression coefficients $b_{1}$ and $b_{2}$ are interpreted as change in the predictand, in standard deviations, per standard deviation change in the predictors, and thus can be used to determine the relative importance of the independent variables to the dependent variable $y$. The $b_{1}$ and $b_{2}$ in Eq. (1) can be estimated by least squares method and are calculated as follows:

$$
\begin{aligned}
& b_{1}=\frac{r_{y x_{1}}-r_{y x_{2}} r_{x_{1} x_{2}}}{\left(1-r_{x_{1} x_{2}}^{2}\right)} \text { and } \\
& b_{2}=\frac{r_{y x_{2}}-r_{y x_{1}} r_{x_{1} x_{2}}}{\left(1-r_{x_{1} x_{2}}^{2}\right)}
\end{aligned}
$$

where $r$ means correlation coefficient (e.g., $r_{y x_{1}}$ indicates the correlation coefficient between $y$ and $x_{1}$ ).

For Eq. (1), the regression variance $s_{\hat{y}}^{2}$ by the regression equation can be calculated as

$$
s_{\hat{y}}^{2}=b_{1} r_{x_{1} y}+b_{2} r_{x_{2} y}
$$

The explained variance by $x_{1}$ and $x_{2}$ in the total variance $\left(s_{y}^{2}=1\right)$ can be calculated as 


$$
\begin{aligned}
& C_{x_{1}}=\frac{b_{1} r_{x_{1} y}}{s_{y}^{2}} \times 100 \%=b_{1} r_{x_{1} y} \times 100 \%, \\
& C_{x_{2}}=\frac{b_{2} r_{x_{2} y}}{s_{y}^{2}} \times 100 \%=b_{2} r_{x_{1} y} \times 100 \%,
\end{aligned}
$$

where the abbreviated notation $C$ means contribution (explained variance).

Partial correlation is also adopted to estimate the pure connection between the predictor and the predictand after removing effect of other predictors. For two variables $x_{1}$ and $y$, the partial correlation after removing the effect of $x_{2}$ is calculated by the following formula:

$$
r_{x_{1} y, x_{2}}=\frac{r_{y x_{1}}-r_{y x_{2}} r_{x_{1} x_{2}}}{\sqrt{\left(1-r_{y x_{2}}^{2}\right)\left(1-r_{x_{1} x_{2}}^{2}\right)}} .
$$

Similarly, the partial correlation between $x_{2}$ and $y$ after removing the effect of $x_{1}$ can be expressed as

$$
r_{x_{2} y, x_{1}}=\frac{r_{y x_{2}}-r_{y x_{1}} r_{x_{1} x_{2}}}{\sqrt{\left(1-r_{y x_{1}}^{2}\right)\left(1-r_{x_{1} x_{2}}^{2}\right)}} .
$$

A comparison between Eqs. (2) and (7) illustrates that partial regression coefficients and partial correlation coefficients are closely linked. The numerators in Eqs. (2) and (7) are the same, and both formulas measure the unique effect of $x_{1}$ on $y$; the numerators in Eqs. (3) and (8) are the same, and both formulas measure the unique effect of $x_{2}$ on $y$.

The significance test of partial correlation coefficient (partial regression coefficient) is based on Student's $t$ distribution:

$$
t=\frac{r_{x_{1} y, x_{2}}}{\sqrt{\frac{1-r_{x_{1} y, x_{2}}^{2}}{n-3}}}
$$

where $t$ follows Student's $t$ distribution with degrees of freedom $n-3$, and $n$ is the size of the sample.

For variables characterized with strong autocorrelation, the effective degree of freedom (denoted by $n^{*}$ ) based on Davis (1976) and Chen (1982) is calculated as follows:

$$
\begin{aligned}
n^{*} & =\frac{n}{T}, \\
T & =\sum_{\tau=1}^{\tau=1 \mathrm{ag}} R_{\mathrm{xx}}(\tau) \times R_{\mathrm{yy}}(\tau), \\
R_{\mathrm{xx}}(\tau) & =\frac{1}{n-\tau} \sum_{t=1}^{n-\tau} x_{t}^{*} \times x_{t+\tau}^{*}, \\
R_{\mathrm{yy}}(\tau) & =\frac{1}{n-\tau} \sum_{t=1}^{n-\tau} y_{t}^{*} \times y_{t+\tau}^{*},
\end{aligned}
$$

where the lag in Eq. (11) is usually taken as one-half of $n$, and the asterisks indicate standardized variables.

\section{Connections between the SAM and SST}

Before analyzing the relative importance of the DJF and MAM SAM on MAM southern extratropical SST, we review some basic features of the DJF and MAM SAM and their direct correlation with southern extratropical SST.

\section{a. Basic features of the DJF and MAM SAM}

The basic feature of the SAM is a foundation for us to understand its correlation with local SST. Figure 1a shows composite differences in the DJF zonal-mean zonal wind (contours) and meridional circulation (streamlines) between high and low SAM years. The high and low SAM years were selected based on the fluctuations of the SAMI beyond one standard deviation. A comparison with climatological DJF zonal-mean circulation (Fig. 1b) illustrates that the Ferrel cell is stronger and shows a slight shift toward the Antarctic in the positive phase of the SAM. Meanwhile, zonal wind through the whole troposphere in the high latitudes increase and that in the middle latitudes decrease, implying a poleward shift of the middle latitude westerly in the positive SAM phase (see also Gong and Wang 1999; Watterson 2000; Limpasuvan and Hartmann 1999; Thompson and Wallace 2000; Li and Wang 2003). Note that the zonal wind anomalies associated with the SAM in the high latitudes are stronger than that in the middle latitudes.

Similar analyses for the MAM are shown in Figs. 1c and $1 \mathrm{~d}$. The characteristics of circulation anomalies during the positive SAM phase in MAM are generally in accordance with those in DJF, which are featured by increased zonal wind in the high latitudes and decreased zonal wind in the middle latitudes. Similarly, the wind anomalies in the high latitudes are stronger than that in the middle latitudes.

\section{b. Correlation between the SAM and contemporaneous SST}

Changes in surface wind may alter local SST. Correlation coefficients between the SAM and contemporaneous zonal-mean SST in DJF and MAM are shown in Fig. $2 \mathrm{a}$ as the dotted and the dashed lines, respectively.

The common feature of the correlations in DJF and MAM is that there is positive correlation in the middle latitudes $\left(48^{\circ}-30^{\circ} \mathrm{S}\right)$ but negative correlation in the high latitudes $\left(70^{\circ}-52^{\circ} \mathrm{S}\right)$, indicating that positive (negative) phases of the SAM tend to cause cooler (warmer) SST in the high latitudes, but warmer (cooler) SST in the middle latitudes. Another common feature is that the 
(a) Composite based on DJF SAM

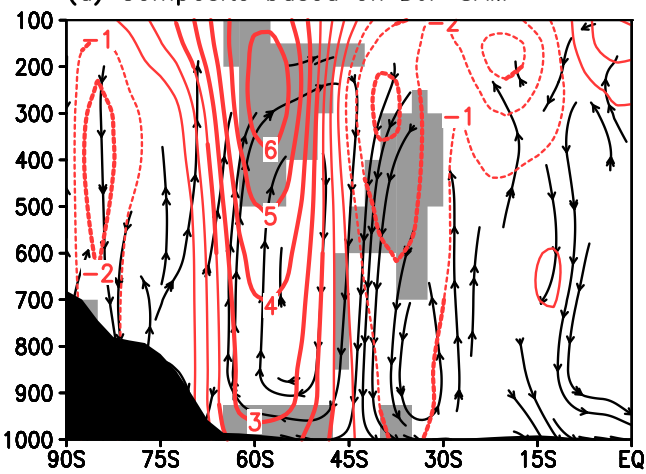

(c) Composite based on MAM SAM

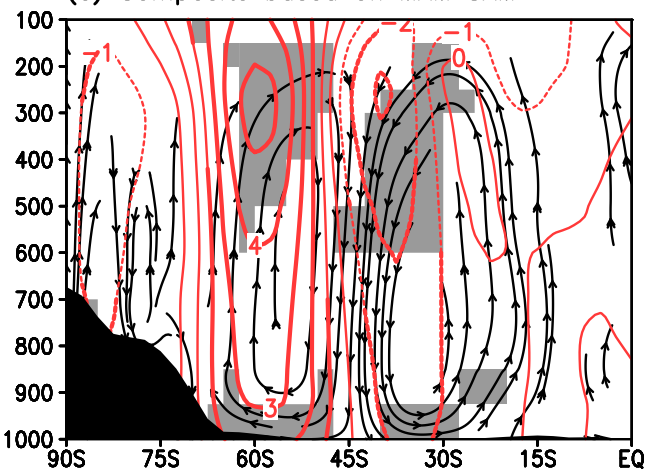

(b) Climatology in DJF

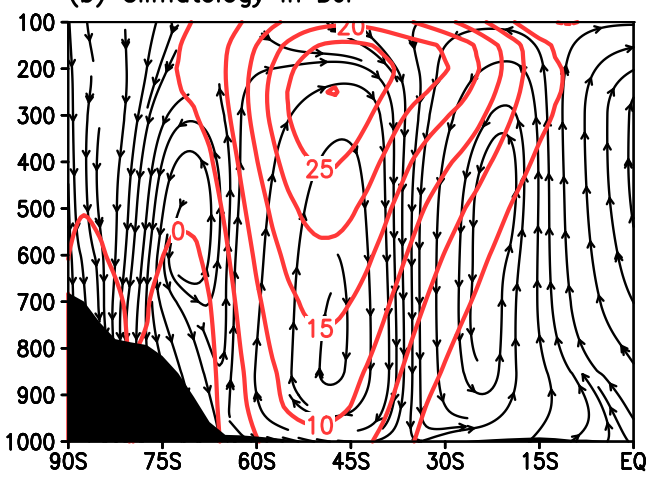

(d) Climatology in MAM

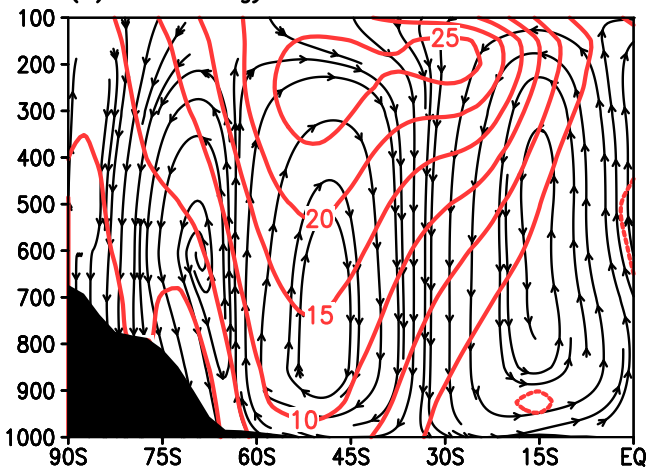

FIG. 1. (a) Composite difference in DJF zonal-mean zonal wind $\left(\mathrm{m} \mathrm{s}^{-1}\right.$, contours) and meridional circulation (streamlines) between high and low DJF SAM years. The high and low SAM years were selected based on the fluctuations of the SAMI beyond one standard deviation. The gray shadings indicate the $95 \%$ significance level for zonal-mean meridional wind. The thick red lines in (a) [and (c)] indicate significance at the $95 \%$ confidence level for zonal-mean zonal wind. The black shadings show the zonal-mean surface pressure. (b) As in (a), but for the climatology. (c),(d) As in (a),(b), but for MAM season.

correlations in high latitudes are stronger than that in the middle latitudes. This similarity between the correlation patterns in DJF and MAM is reasonable because the zonal wind anomalies caused by the DJF and MAM SAM show a degree of consistency (Figs. 1a and 1c). One difference between these correlation patterns in DJF and MAM as shown in Fig. 2a is that the correlation in MAM is weaker than that in DJF. Another difference is that the negative-correlated region in MAM is narrower than that in DJF.

As noted before, this SAM-related dipolelike SSTA pattern in the southern extratropics is referred to as the SOD. The SODI is used to reflect the temporal variability of the SOD variability (details in section 2a). The correlation matrix between the SAMI and the SODI is shown in Table 1. It is found that the correlations between the SAMI and the contemporaneous SODI are 0.71 and 0.48 in DJF and MAM, respectively. Both of them are significant at the $95 \%$ confidence level, whereas the correlation in MAM is weaker than that in
DJF, which is in accordance with what has been shown in Fig. 2a.

Besides, the correlation maps of the SAM and SST on the horizontal plane in DJF and MAM are shown in Figs. 3a and 3c, respectively. In spite of the zonal asymmetry, the dipolelike SSTA pattern is also evident in DJF (Fig. 3a) but with a weaker strength in MAM (Fig. 3c). Note that there is zonal asymmetry of the correlation coefficients between the SAM and SST (see also Sen Gupta and England 2006). There are many interesting ideas that help us understand the deviations from zonal symmetry of the climate, but this is beyond the scope of the present study. We mainly concentrate on zonal-mean variability.

\section{c. Removing the ENSO signal}

The SAM and ENSO are closely correlated in the austral warm seasons (e.g., Karoly 1989; Seager et al. 2003; Zhou and Yu 2004; Ciasto et al. 2015). It can be seen in Table 1 that the correlation between the SAMI 
(a) Corr. between SAM and Zonal-mean SST

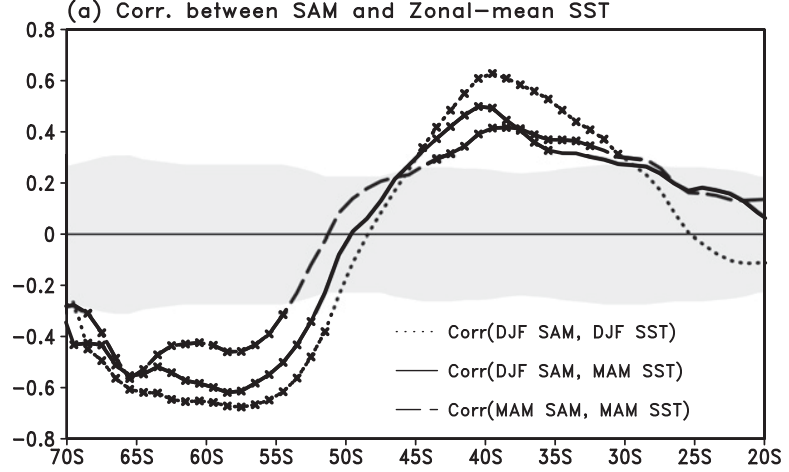

(b) Corr between SAM and Zonal-mean SST (remove ENSO)

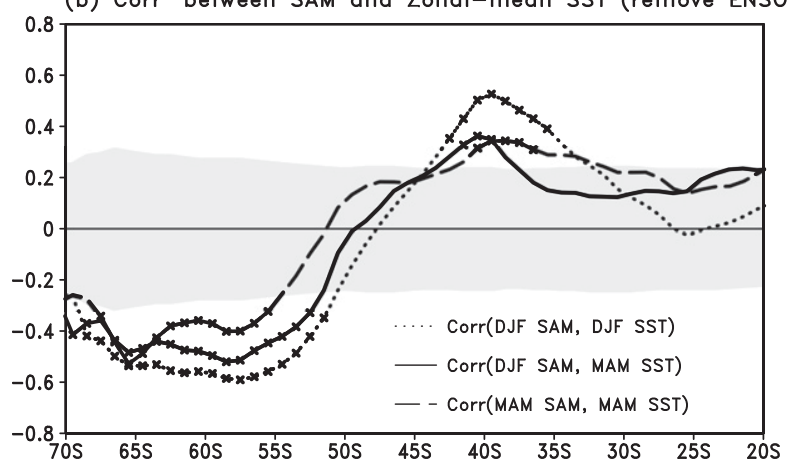

FIG. 2. (a) Correlation coefficients between the SAM and southern extratropical zonal-mean SST. The dotted line indicates correlation between the DJF SAM and DJF SST, the solid line between the DJF SAM and MAM SAM, and dashed line between the MAM SAM and MAM SST. The crosses on the lines represent significance at the $95 \%$ confidence level. The gray areas indicate significance is at $<80 \%$ confidence level for the correlation between the DJF SAM and MAM SST. (b) As in (a), but after removing the ENSO signals. For DJF SST, we remove the DJF ENSO signal and for MAM SST, both the DJF and MAM ENSO signals.

and ENSO is -0.41 in DJF, which is stronger than that in MAM (-0.31), further confirming the relationship between the SAM and ENSO as revealed by previous studies (Zhou and Yu 2004; Gong et al. 2010; Ding et al. 2011, 2012). In addition, there is also a close linkage between ENSO and Southern Hemisphere extratropical
SST. It can be seen in Table 1 that the correlation between ENSO and the SOD is $-0.66(-0.55)$ in DJF (MAM), which is consistent with previous studies (e.g., Ciasto and Thompson 2008; Ciasto et al. 2015). Therefore, it is necessary to verify that the correlation between the SAM and contemporaneous southern extratropical SST is not only a reflection of their connection with ENSO.

First, partial correlations were conducted to detect the connection between the SAMI and the SODI after removing the ENSO signal. The partial correlations between the SAMI and contemporaneous SODI in DJF and MAM after removing ENSO are 0.64 and 0.39 (Table 1), respectively. Compared with the raw correlation before removing the ENSO signal (0.71 and 0.48), the strengths of correlations weaken but are still significant at the $95 \%$ confidence level, implying the robustness of the linkage between the SAM and the SOD in DJF and MAM. Besides, the partial correlations between ENSO and the SOD also weaken from -0.66 to -0.58 in DJF and from -0.55 to -0.48 in MAM after removing the SAM signal. The above analyses illustrate that the correlations among the SOD, the SAM, and ENSO influence each other because of the linkage between the SAM and ENSO. The correlation between the SAM and contemporaneous SOD is still robust without the ENSO variability, implying their relationship is not only a reflection of ENSO influences.

In addition, similar correlation analyses as in Fig. 2a but after removing the ENSO signal are shown in Fig. 2b. For DJF SST, we remove the DJF ENSO signal. For MAM SST, we remove both the DJF and MAM ENSO signals. By a comparison between Figs. $2 a$ and $2 b$, it is found that the correlations between the SAM and contemporaneous SST in DJF and MAM weaken after removing the ENSO signal. The decrease of correlation is stronger in the middle latitudes than that in the high latitudes, indicating that the perturbation of ENSO on the SAM-related SSTA is stronger in the middle latitudes than that in the high latitudes. Because the linkage between the SAM and the ENSO is stronger in DJF than that in MAM (Table 1),

TABLE 1. Correlation coefficient matrix between DJF SAMI, MAM SAMI, DJF SODI, MAM SODI, DJF ENSO, and MAM ENSO for the period 1978/79-2011/12. The italics indicate that the value is not significant at the $95 \%$ confidence level. The numbers in parentheses indicate partial correlation coefficients. For the SAM cases, partial correlation means removing the ENSO signal and for the ENSO cases, the SAM signal.

\begin{tabular}{lclllll}
\hline \hline & DJF SAMI & MAM SAMI & DJF SODI & MAM SODI & DJF ENSO & MAM ENSO \\
\hline DJF SAMI & 1 & $0.39(0.33)$ & $0.71(0.64)$ & $0.61(0.51)$ & -0.41 & -0.43 \\
MAM SAMI & & 1 & 0.21 & $0.48(0.39)$ & -0.24 & -0.31 \\
DJF SODI & & & 1 & $0.87(0.80)$ & $-0.66(-0.58)$ & -0.59 \\
MAM SODI & & & & & $-0.58(-0.45)$ & $-0.55(-0.48)$ \\
DJF ENSO & & & & & 1 & 0.87 \\
MAM ENSO & & & & & 1 \\
\hline
\end{tabular}


(a) Corr (DJF SAM, DJF SST)

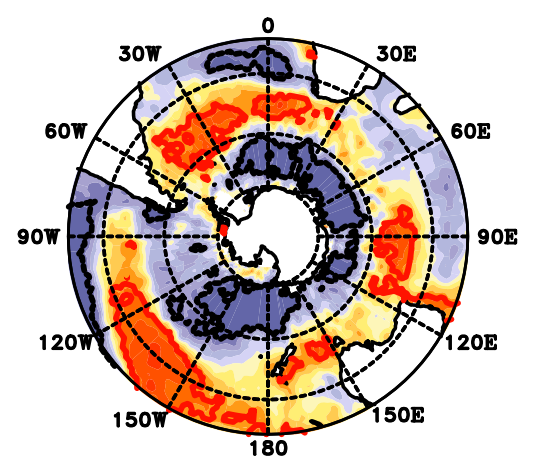

(d) P_Corr (DJF SAM, DJF SST)

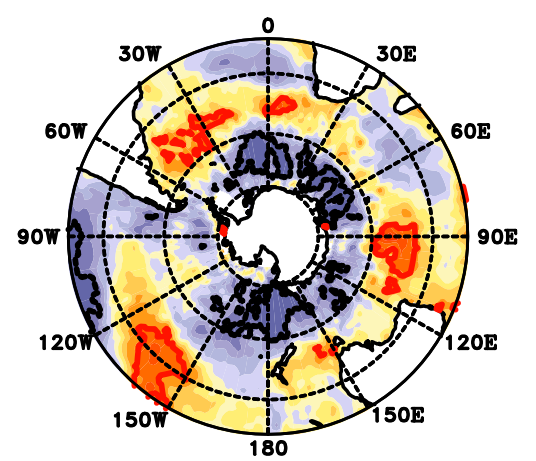

(b) Corr (DJF SAM, MAM SST)

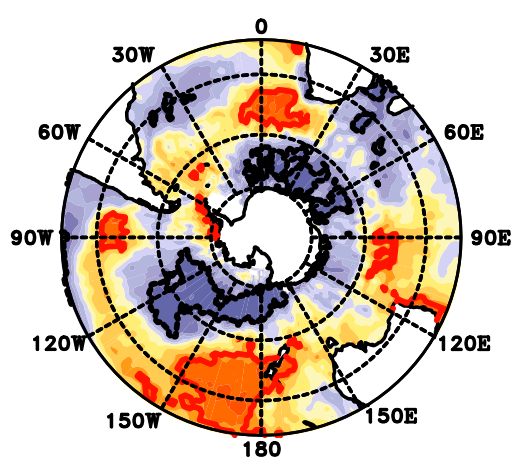

(e) P_Corr (DJF SAM, MAM SST)

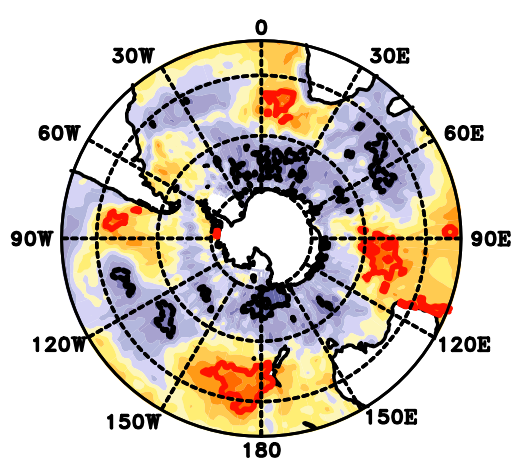

(c) Corr (MAM SAM, MAM SST)

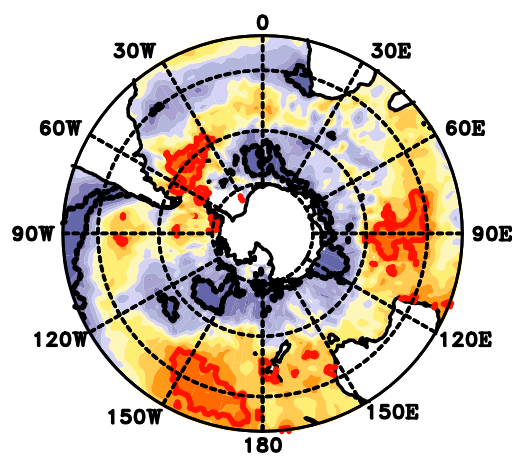

(f) P_Corr (MAM SAM, MAM SST)

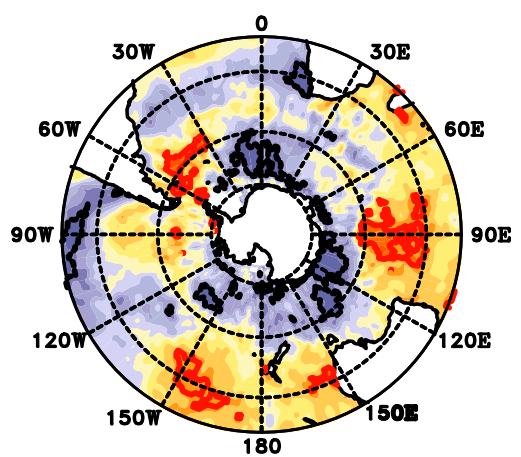

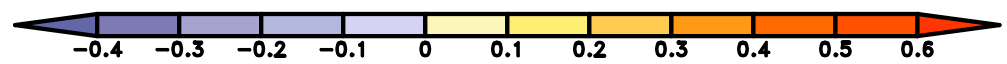

FIG. 3. (a) Correlation coefficients between the DJF SAM and DJF SST. (b) As in (a), but for the DJF SAM and MAM SST. (c) As in (a), but for the MAM SAM and MAM SST. The thick contour lines denote the $95 \%$ confidence level. (d)-(f) As in (a)-(c), but for the partial correlation after removing the ENSO signals. For DJF SST, we remove the DJF ENSO signal and for MAM SST, both the DJF and MAM ENSO signals.

the weakening of the correlation after removing the ENSO signal in Fig. 2b is more evident in DJF than that in MAM, both in the middle and high latitudes. However, in spite of the weakened strength, the dipolelike correlation patterns in DJF and MAM are still significant, indicating again that the correlation between the SAM and the contemporaneous SOD is not only a reflection of their relationship with ENSO.

Furthermore, we recalculate the correlation coefficients in Figs. $3 \mathrm{a}$ and $3 \mathrm{c}$ after removing the ENSO signal, and the results are showed in Figs. 3d and 3f. Compared with the zonal-mean component in Fig. 2, the changes in the zonal asymmetric component after removing ENSO signal (Fig. 3) are larger than that in the zonal-mean component (Fig. 2). This is possibly due to the fact that the zonal symmetric component is dominated in the SAM signal, while the influence of ENSO on SST is featured by stronger zonal asymmetry. Although removing the ENSO signal reduces the correlation between the SAM and southern extratropical SST, the large-scale correlation patterns in Figs. 3d and 3f are generally consistent with that in Figs. 3a and 3c. The spatial correlations between Figs. $3 \mathrm{a}$ and $3 \mathrm{~d}, 3 \mathrm{c}$ and $3 \mathrm{f}$ reach 0.8 and are significant at the $95 \%$ confidence level, indicating once more the robustness of correlation between the SAM and southern extratropical SST. There are many interesting ideas that help us understand the zonal asymmetry of the SSTA, but this is beyond the focus of the present study, which is the zonal-mean component of SSTA.

In short, although there are linkages between the SAM, ENSO, and the SOD, the connections between the SAM and the contemporaneous SOD in DJF and MAM still show robustness after removing the ENSO variability.

\section{d. Cross-seasonal influence of the DJF SAM on MAM SST}

As shown in Table 1, the cross-seasonal correlation between the DJF SAMI and MAM SODI is 0.61, which 
TABLE 2. List of the primary abbreviations and their meanings in this study. Type reflects the part/method where the abbreviation appears. In particular, 1 indicates the general representation of the air-sea system; 2, the direct lead-lag correlation; 3, the SST decomposition based on the unary regression; and 4, the PSD.

\begin{tabular}{|c|c|c|}
\hline Abbreviations & Type & Meanings \\
\hline$A$ & 1 & $\begin{array}{l}\text { The large-scale atmospheric signal, which plays a dominant role in controlling large-scale SSTA } \\
\text { pattern }(S) \text {. }\end{array}$ \\
\hline$S$ & 1 & The large-scale SSTA pattern. \\
\hline$t-1, t$ & 1 & Two adjacent seasons on the timeline. \\
\hline$A(t)$ & 1 & $A(t)$ can be separated to $A_{P}(t)$ and $A_{H}(t)$ under the framework of the PSD. \\
\hline$S(t-1)$ & 1 & $S(t-1)$ can be separated to $S_{A}(t-1)$ and $S_{R}(t-1)$ under the framework of the PSD. \\
\hline$a_{P}, C_{P}$ & 2 & $\begin{array}{l}\text { The regression coefficient }\left(a_{P}\right) \text { of MAM SST on the DJF SAM and the corresponding explained } \\
\text { variance }\left(C_{P}\right) \text {. See Eqs. }(25) \text { and }(27) \text {. }\end{array}$ \\
\hline$a_{\mathrm{HP}}, C_{\mathrm{HP}}$ & 2 & $\begin{array}{l}\text { The regression coefficient }\left(a_{\mathrm{HP}}\right) \text { of MAM SST on the MAM SAM and the corresponding explained } \\
\text { variance }\left(C_{\mathrm{HP}}\right) \text {. See Eqs. }(26) \text { and }(28) \text {. }\end{array}$ \\
\hline$S_{P}(t)$ & 3 & $\begin{array}{l}\text { The persistent component in } S(t) \text { derived from the SST decomposition based on the unary } \\
\text { regression analysis. See Eq. (29). }\end{array}$ \\
\hline $\begin{array}{l}A_{P}(t), a_{\mathrm{AP}} \\
\quad C_{\mathrm{AP}}\end{array}$ & 4 & $\begin{array}{l}A_{P}(t) \text { is the component associated with } A(t-1) ; a_{\mathrm{AP}} \text { and } C_{\mathrm{AP}} \text { are the partial regression coefficient } \\
\text { and the explained variance corresponding to } A_{P}(t) \text { in Eq. (18). See Eqs. (14), (18), and (23). }\end{array}$ \\
\hline $\begin{array}{l}A_{H}(t), a_{\mathrm{AH}} \\
\quad C_{\mathrm{AH}}\end{array}$ & 4 & $\begin{array}{l}A_{H}(t) \text { is independent of } A(t-1) \text { and } A_{P}(t) ; a_{\mathrm{AH}} \text { and } C_{\mathrm{AH}} \text { are the partial regression coefficient } \\
\text { and the explained variance corresponding to } A_{H}(t) \text { in Eq. (18). See Eqs. (15), (18), and (23). }\end{array}$ \\
\hline $\begin{array}{l}S_{A}(t-1), a_{\mathrm{SP} \_\mathrm{A}}, \\
\quad C_{\mathrm{SP} \_\mathrm{A}}\end{array}$ & 4 & $\begin{array}{l}S_{A}(t-1) \text { is the component caused by } A(t-1) ; a_{\mathrm{SP} \_\mathrm{A}} \text { and } C_{\mathrm{SP} \_\mathrm{A}} \text { are the partial regression } \\
\text { coefficient and the explained variance corresponding to } S_{A}(t-1) \text { in Eq. (18). See Eqs. }(16),(18) \text {, } \\
\text { and (23). }\end{array}$ \\
\hline $\begin{array}{l}S_{R}(t-1), a_{\mathrm{SP} \_\mathrm{R}} \\
\quad C_{\mathrm{SP} \_\mathrm{R}}\end{array}$ & 4 & $\begin{array}{l}S_{R}(t-1) \text { is independent of } A(t-1) \text { and } S_{A}(t-1) ; a_{\mathrm{SP}_{\mathrm{R}} \mathrm{R}} \text { and } C_{\mathrm{SP}_{-} \mathrm{R}} \text { are the partial regression } \\
\text { coefficient and the explained variance corresponding to } S_{R}(t-1) \text { in Eq. (18). See Eqs. (17), (18), } \\
\text { and (23). }\end{array}$ \\
\hline$C_{\mathrm{AH} \_\mathrm{R}}$ & 4 & $\begin{array}{l}\text { The residual explained variance which cannot be explained by Eq. (18). Its calculation can be } \\
\text { found in Eq. (24). }\end{array}$ \\
\hline
\end{tabular}

is significant at the $95 \%$ confidence level. The partial correlation after removing the ENSO signal is 0.51, which is still significant, verifying that the DJF SAM can imprint its signal on MAM SOD.

In addition, the cross-seasonal correlation between the DJF SAM and MAM zonal-mean SST is shown in Fig. $2 \mathrm{a}$ as the solid line. It can be seen that the DJF SAM is correlated with SST in the following MAM, and the dipolelike SOD pattern is evident. The similar cross-seasonal correlation between the DJF SAM and MAM zonal-mean SST after removing the ENSO signal is shown in Fig. $2 \mathrm{~b}$ as the solid line. Although the strength of the correlation is weaker after removing the ENSO signal, the dipolelike SSTA is still clear, implying that the DJF SAM may imprint their signals on MAM SST without the effect of ENSO. Furthermore, Figs. $3 \mathrm{~b}$ and $3 \mathrm{e}$ also illustrate the cross-seasonal linkage between the DJF SAM and MAM SST on the horizontal panel.

Above all, the MAM SAM is associated with MAM SOD; nevertheless, the DJF SAM may also regulate MAM SOD. Therefore, MAM SST field in the southern extratropics contains anomalies both from the DJF SAM and the MAM SAM. We next explore the relative importance of the DJF and MAM SAM in modulating MAM southern extratropical SSTA.

\section{Methods to detect the relative importance of the DJF and MAM SAM in influencing MAM SST}

The three approaches used to detect the relative importance of the DJF and MAM SAM in influencing MAM SST are introduced in this section, including the PSD (sections $4 a$ and $4 b$ ), the direct lead-lag correlation (section 4c), and SST decomposition based on the unary regression method (section $4 \mathrm{~d}$ ). The results from these approaches are shown in section 5 . The primary abbreviations and their meanings are listed in Table 2 for easy checking.

\section{a. The framework of the PSD}

The PSD is based upon a conceptual framework of simplified extratropical air-sea interactions on seasonal scale, shown schematically in Fig. 4, in which one largescale atmospheric signal ( $A$; e.g., SAM) plays a dominant role in controlling large-scale SSTA pattern $(S$; e.g., SOD). The downward arrows indicate the influence of $A$ on $S$, and the upward dashed arrows denote the feedback of $S$ on $A$. The $t-1$ and $t$ indicate two adjacent seasons on the timeline. Here, these two seasons are the DJF and the following MAM. The horizontal arrows represent the persistence of $A$ and $S$. The persistence of SST is well established, as aforementioned in section 1. 


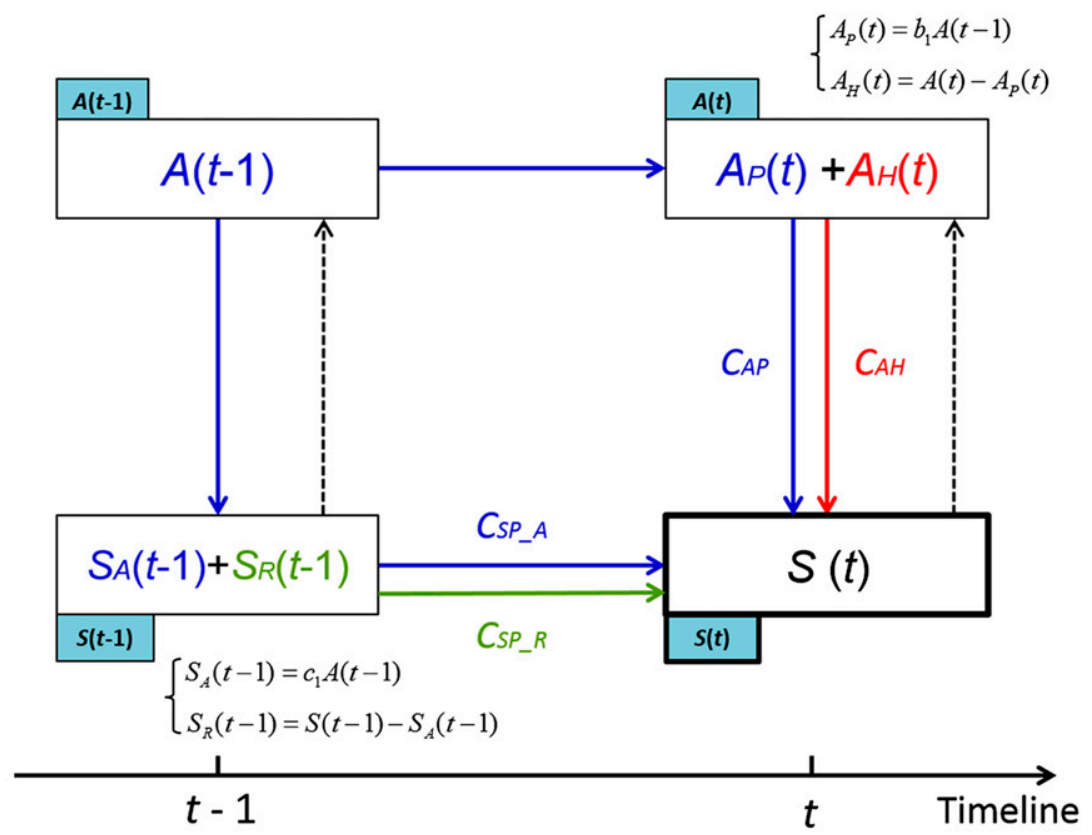

Persistent Signal Decomposition (PSD):

$$
\begin{gathered}
\hat{S}(t)=a_{A H} A_{H}(t)+a_{A P} A_{P}(t)+a_{S P_{-} A} S_{A}(t-1)+a_{S P_{-} R} S_{R}(t-1) \\
\operatorname{Var}(S(t))=\underset{\downarrow}{C_{A H}+C_{A P}+C_{S P_{-} A}+C_{S_{-} R}+C_{A H_{-} R}} \\
\text { homochronous component related to } A H(t) \quad \text { persistent component related to } A(t-1)
\end{gathered}
$$

FIG. 4. Schematic of the persistent signal decomposition (PSD). Here $A$ and $S$ represent the dominant atmospheric signal (e.g., SAM) and the corresponding SSTA pattern (e.g., SOD), respectively. The $t-1$ and $t$ indicate two consecutive seasons on the timeline. The horizontal arrows represent the persistence of $A$ and $S$. The downward arrows indicate the influence of $A$ on $S$ and the upward dashed arrows denote feedback of $S$ on $A$. The symbols [ $A(t-1), A(t), S$ $(t-1)$, and $S(t)]$ in the small blue shaded boxes represent raw signals before decomposition. The meanings of the abbreviations $\left[A_{P}(t), A_{H}(t), S_{A}(t-1), S_{R}(t-1), a_{\mathrm{AP}}, a_{\mathrm{AH}}, a_{\mathrm{SP} \_\mathrm{A}}, a_{\mathrm{SP} \_\mathrm{R}}\right.$, $C_{\mathrm{AP}}, C_{\mathrm{AH}}, C_{\mathrm{SP}_{-} \mathrm{A}}$, and $\left.C_{\mathrm{SP}_{-} \mathrm{R}}\right]$ and the formula are in section 4.

The persistence of the SAM is also taken into consideration because its autocorrelation is significant. The autocorrelation between the DJF SAM and MAM SAM is shown in Table 1 , which is 0.39 and is significant at the $95 \%$ confidence level. Although the persistence of the SAM on a daily scale is only several days (Ciasto and Thompson 2008), its intraseasonal autocorrelation is relatively strong. Many low-frequency modes have statistically significant persistence at interseasonal scale as revealed by previous studies (e.g., Barnston and Livezey 1987). The mechanism of the interseasonal persistence of the SAM is, however, beyond the scope of this study.

In Fig. 4, the $A(t)$ can be separated to two independent parts. The first part $A_{P}(t)$ is associated with $A(t-1)$ due to signal persistence, and the subscript $P$ means persistence; the second part $A_{H}(t)$ is independent of $A(t-1)$ and $A_{P}(t)$, and the subscript $H$ represents homochromous or contemporaneous. Based on standardized regression equation, $A_{P}(t)$ and $A_{H}(t)$ are expressed as

$$
\begin{aligned}
& A_{P}(t)=b_{1} A(t-1) \quad \text { and } \\
& A_{H}(t)=A(t)-A_{P}(t),
\end{aligned}
$$

where $b_{1}$ is the regression coefficient between $A(t)$ and $A(t-1)$.

The $S(t-1)$ can be also separated into two independent parts, $S_{A}(t-1)$ caused by $A(t-1)$, and the residual part, $S_{R}(t-1)$, which is independent of $A(t-1)$ and $S_{A}(t-1)$. The subscript A in $S_{A}(t-1)$ represents 
component associated with the atmospheric signal $A(t-1)$, and the subscript $R$ in $S_{R}(t-1)$ means the residual part which is not associated with $A(t-1)$. Similarly, based on standardized regression equation, $S_{A}(t-1)$ and $S_{R}(t-1)$ are expressed as

$$
\begin{aligned}
& S_{A}(t-1)=c_{1} A(t-1) \quad \text { and } \\
& S_{R}(t-1)=S(t-1)-S_{A}(t-1),
\end{aligned}
$$

where $c_{1}$ is the regression coefficient between $A(t-1)$ and $S(t-1)$.

It is evident in Fig. 4 that the cross-seasonal influence of $A(t-1)$ on $S(t)$ occurs in two ways. One is through the persistence of the atmospheric variable $A(t-1)$, which imprints its signal on $S(t)$ through $A_{P}(t)$. The second is through the persistence of SST $S(t-1)$, which imprints its signal on $S(t)$ through $S_{A}(t-1)$. Both the persistence of SST and the atmospheric signal are taken into consideration for the cross-seasonal influence of $A(t-1)$ on $S(t)$.

Based on the above analyses, $S(t)$ can be expressed by a quaternion standardized regression equation:

$$
\begin{aligned}
\hat{S}(t)= & a_{\mathrm{AH}} A_{H}(t)+a_{\mathrm{AP}} A_{P}(t)+a_{\mathrm{SP}_{-} \mathrm{A}} S_{A}(t-1) \\
& +a_{\mathrm{SP} \_\mathrm{R}} S_{R}(t-1),
\end{aligned}
$$

where $\hat{S}(t)$ is the fitting of $S(t)$ by the linear regression; and $a_{\mathrm{AH}}, a_{\mathrm{AP}}, a_{\mathrm{SP}_{-} \mathrm{A}}$, and $a_{\mathrm{SP} \_\mathrm{R}}$ are the standardized partial regression coefficients.

\section{b. The calculation of the PSD}

To quantify the contribution of different terms on the right-hand side of Eq. (18) to $S(t)$, one way is to calculate the regression coefficient $\left(a_{\mathrm{AH}}, a_{\mathrm{AP}}, a_{\mathrm{SP} \_\mathrm{A}}\right.$, and $\left.a_{\mathrm{SP} \_\mathrm{R}}\right)$ and their corresponding explained variances. However, calculating the regression coefficients in multiple regression equation requires a matrix solution and is relatively complex. To simplify the calculation procedure for the regression coefficient $\left(a_{\mathrm{AH}}, a_{\mathrm{AP}}, a_{\mathrm{SP} \_\mathrm{A}}\right.$, and $\left.a_{\mathrm{SP} \_\mathrm{R}}\right)$ and their corresponding explained variances, we first simplify the quaternion regression equation in Eq. (18). It is easy to know from Eqs. (14) and (15) that $A_{H}(t)$ and $A_{P}(t)$ are independent of each other. Similarly, $S_{A}(t-1)$ and $S_{R}(t-1)$ are independent according to Eqs. (16) and (17). Besides, it can be inferred that $A_{H}(t)$ and $S_{A}(t-1)$ are independent, and $A_{P}(t)$ and $S_{R}(t-1)$ are also independent. Therefore, to conveniently calculate the regression coefficients, we can simplify the quaternion regression equation in Eq. (18) to two binary linear standardized regressions:

$$
\begin{aligned}
& \tilde{S}(t)=a_{\mathrm{AP}} A_{P}(t)+a_{\mathrm{SP}_{-} \mathrm{A}} S_{A}(t-1) \quad \text { and } \\
& \widehat{S}(t)=a_{\mathrm{AH}} A_{H}(t)+a_{\mathrm{SP}_{-} \mathrm{R}} S_{R}(t-1),
\end{aligned}
$$

where $\tilde{\mathrm{S}}(t)$ and $\widehat{S}(t)$ are the fittings of $S(t)$ by Eqs. (19) and (20), respectively. Although the fittings of $S(t)$ by Eqs. (19)-(20) are different from that by Eq. (18), the standardized regression coefficients $\left(a_{\mathrm{AH}}, a_{\mathrm{AP}}, a_{\mathrm{SP}_{-} \mathrm{A}}\right.$, $\left.a_{\mathrm{SP} \_\mathrm{R}}\right)$ by the least squares method from Eqs. (18)-(20) are the same. For brevity, we use $\tilde{\mathrm{S}}(t)$ to represent the fitting of $S(t)$ in the following analysis. Note that the $\tilde{\mathrm{S}}(t)$ by different regression equations may be different. Furthermore, given that the variables in Eq. (19), $A_{P}(t)$ and $S_{A}(t-1)$, are highly correlated with each other, it is impossible to calculate $a_{\mathrm{AP}}$ and $a_{\mathrm{SP}_{-} \mathrm{A}}$ because the denominators in Eqs. (2) and (3) are almost equal to zero. We further make a transformation of Eq. (19) to two equations to calculate $a_{\mathrm{AP}}$ and $a_{\mathrm{SP}_{-} \mathrm{A}}$ separately:

$$
\begin{aligned}
& \tilde{S}(t)=a_{\mathrm{AP}} A_{P}(t)+a^{\prime} S(t-1) \quad \text { and } \\
& \tilde{S}(t)=a^{\prime} A(t)+a_{\mathrm{SP} \_\mathrm{A}} S_{A}(t-1) .
\end{aligned}
$$

Therefore, we can calculate $a_{\mathrm{AH}}, a_{\mathrm{AP}}, a_{\mathrm{SP} \_\mathrm{A}}$, and $a_{\mathrm{SP} \_\mathrm{R}}$ based on the simplified binary regression equations in Eqs. (20)-(22) rather than based on the quaternion regression equation in Eq. (18). The solutions to standardized binary regression coefficients can be found from Eqs. (2) and (3), and the corresponding explained variances are shown in Eqs. (5) and (6).

The explained variances of $a_{\mathrm{AH}}, a_{\mathrm{AP}}, a_{\mathrm{SP} \_\mathrm{A}}$, and $a_{\mathrm{SP} \_\mathrm{R}}$ are referred to as $\mathrm{C}_{\mathrm{AH}}, C_{\mathrm{AP}}, \mathrm{C}_{\mathrm{SP} \_\mathrm{A}}$, and $\mathrm{C}_{\mathrm{SP} \_\mathrm{R}}$. The total explained variance of $S(t)$ is separated to the following parts:

$\operatorname{Var}[S(t)]=C_{\mathrm{AH}}+C_{\mathrm{AP}}+C_{\mathrm{SP} \__{-} \mathrm{A}}+C_{\mathrm{SP} \_\mathrm{R}_{-}}+C_{\mathrm{AH} \_\mathrm{R}}$,

where Var means variance, and $C_{\mathrm{AH} \_\mathrm{R}}$ represents the residual explained variance that cannot be explained by Eq. (18), which indicates the contribution from other contemporaneous influencing factor of $S(t)$ rather than $A(t)$. The subscript $R$ means the residual part that is not associated with the atmospheric factor $A$. The $C_{\mathrm{AH} \_\mathrm{R}}$ is calculated as follows:

$C_{\mathrm{AH} \_\mathrm{R}}=\operatorname{Var}[S(t)]-C_{\mathrm{AH}}-C_{\mathrm{AP}}-C_{\mathrm{SP}_{-} \mathrm{A}}-C_{\mathrm{SP}_{-} \mathrm{R}}$.

The other terms on the right side of Eq. (24) have the following meanings:

1) $C_{\mathrm{AH}}$ represents the component that is induced by the homochronous influence of $A_{H}(t)$ on $S(t)$ without any contribution from the persistent component.

2) $C_{\mathrm{AP}}$ and $C_{\mathrm{SP} \_\mathrm{A}}$ are associated with the persistence of $A(t-1)$ and $S(t-1)$, respectively, and reflect the two ways in which the cross-seasonal influence of $A(t-1)$ on $S(t)$ can occur. The sum of these two 
terms describes the total cross-seasonal influence of $A(t-1)$ on $S(t)$.

3) $C_{\mathrm{SP}_{-} \mathrm{R}}$ is the component caused by persistence of SSTA that is not associated with $A(t-1)$.

Detecting the relative importance of the DJF and MAM SAM in modulating MAM SST, which is the focus of our work, can be regarded as a comparison between contribution of $C_{\mathrm{AH}}$ and the sum of $C_{\mathrm{AP}}$ and $C_{\mathrm{SP}-\mathrm{A}}$ to total MAM SST.

\section{c. Lead-lag correlation}

The direct correlations of MAM SST with the DJF and MAM SAM are equal to the regression coefficients in the following standardized unary regression equations:

$$
\begin{aligned}
& \tilde{S}(t)=a_{P} A(t-1) \quad \text { and } \\
& \tilde{S}(t)=a_{\mathrm{HP}} A(t),
\end{aligned}
$$

where $a_{P}$ and $a_{\mathrm{HP}}$ are the standardized regression coefficients, and other symbols have the same meanings as in previous sections. The subscript $P$ indicates persistence, and the subscript HP means component including both homochronous and persistent signals. The explained variances corresponding to $a_{P}$ and $a_{\mathrm{HP}}$ are expressed as follows:

$$
\begin{aligned}
C_{P} & =a_{P}^{2} \quad \text { and } \\
C_{\mathrm{HP}} & =a_{\mathrm{HP}}^{2} .
\end{aligned}
$$

As aforementioned before, $a_{P}\left(C_{P}\right)$ is used to reflect the linkage between $A(t-1)$ and $S(t)$ in the direct leadlag correlation. Compared with the PSD, it is found that the $C_{P}$ can be treated as a combination of $C_{\mathrm{AP}}$ and $C_{\mathrm{SP} \_\mathrm{A}}$, indicating that the cross-seasonal connection between $A(t-1)$ and $S(t), C_{P}$, is a combination of the atmospheric persistence $\left(C_{\mathrm{AP}}\right)$ and SST persistence $\left(C_{\mathrm{SP} \_\mathrm{A}}\right)$. Hence, the ways to quantify the cross-seasonal influence of $A(t-1)$ on $S(t)$ are consistent in the direct lead-lag correlation $\left(C_{P}\right)$ and in the PSD (the sum of $C_{\mathrm{AP}}$ and $C_{\mathrm{SP} \_\mathrm{A}}$ ); only the PSD can distinguish the persistence caused by the atmosphere $\left(C_{\mathrm{AP}}\right)$ and that by the SST $\left(C_{\mathrm{SP}_{-} \mathrm{A}}\right)$. However, one of the significant difference between the PSD and the direct lead-lag correlation is the way to quantify the homochronous influence of $A(t)$ on $S(t)$. In particular, the direct lead-lag correlation uses $a_{\mathrm{HP}}\left(C_{\mathrm{HP}}\right)$ to reflect this homochronous influence, while the PSD uses $a_{\mathrm{AH}}\left(C_{\mathrm{AH}}\right)$. The $a_{\mathrm{AH}}\left(C_{\mathrm{AH}}\right)$ in the PSD only contains the homochronous component by conducting SST decomposition, while the $a_{\mathrm{HP}}\left(C_{\mathrm{HP}}\right)$ contains a persistent component caused by the $A(t-1)$. Therefore, $a_{\mathrm{AH}}\left(C_{\mathrm{AH}}\right)$ from the PSD is more accurate in reflecting the homochronous linkage between $A(t)$ and
$S(t)$. It will be shown in section $5 \mathrm{c}$ that $a_{\mathrm{AH}}\left(C_{\mathrm{AH}}\right)$ is indeed different from $a_{\mathrm{HP}}\left(C_{\mathrm{HP}}\right)$.

\section{d. SST decomposition based on unary regression}

The unary regression method is employed to decompose the MAM SST to a persistent component related to DJF SST and a nonpersistence component. The persistent component of the $S(t)$, referred to as $S_{p}(t)$, can be calculated according to the following formula:

$$
S_{P}(t)=q_{1} S(t-1)
$$

where $q_{1}$ is the regression coefficient between $S(t)$ and $S(t-1)$. Dividing both sides of Eq. (29) by $S(t-1)$ and multiply by $100 \%$, we get

$$
\frac{S_{P}(t)}{S(t-1)} \times 100 \%=q_{1} \times 100 \%=\mathrm{pr}_{1},
$$

where $\mathrm{pr}_{1}$ indicates the percentage of the $S(t-1)$ that can persist to the following time $t$ in the total $S(t-1)$. In addition, we can calculate the percentage of persistent component $S_{P}(t)$ in the $S(t)$ :

$$
\frac{S_{P}(t)}{S(t)} \times 100 \%=\mathrm{pr}_{2},
$$

where this percentage is referred to as $\mathrm{pr}_{2}$.

The difference between the above unary regression and the PSD is the way to conduct SST decomposition. The unary regression cannot distinguish the persistent SST component related with one specific atmospheric factor from the total persistent component, while it will be shown in section 5c that the PSD could separate the SAM-related SST persistence from the total SST persistence.

\section{Results}

\section{a. Lead-lag correlation}

The lead-lag correlation coefficients of the MAM SODI with sea level pressure are shown in Fig. 5. The correlated sea level pressure field shows a positive SAM phase from a lead of -4 months through 0 month (Figs. 5a-d). The SAM patterns of the correlation coefficients reach a maximum at a -3 -month lead (i.e., sea level pressure leads by 3 months; Fig. 5b), and then continuously decrease from a -2 -month lead (Fig. 5c) to a 0-month lead (Fig. 5e). It indicates that SAM-like atmospheric anomalies in DJF could produce a dipolelike SSTA pattern in MAM. However, the correlation between the MAM SOD and MAM sea level pressure shows a weaker SAM-like pattern (Figs. 5d-f). The 
(a) -4 month (DEC)

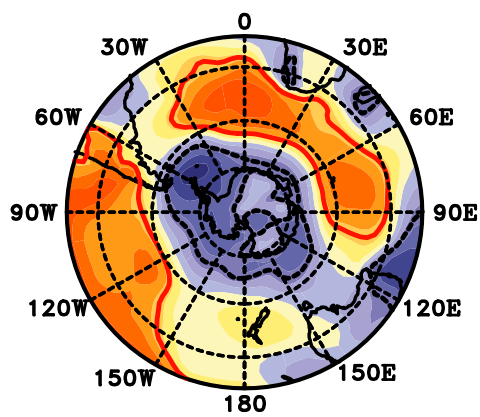

(d) -1 month (MAR)

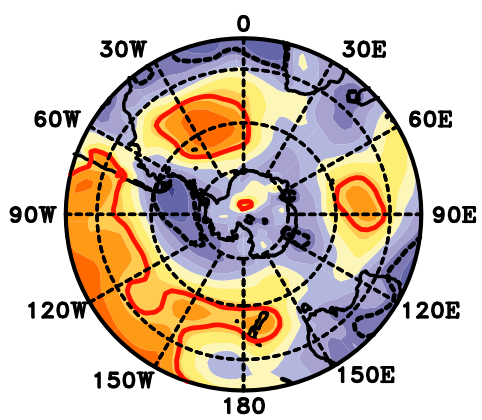

(g) +2 month (JUN)

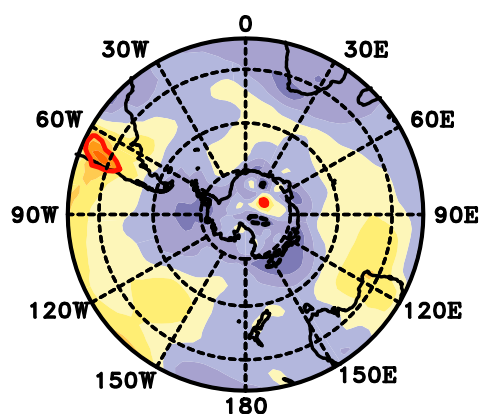

(b) -3 month (JAN)

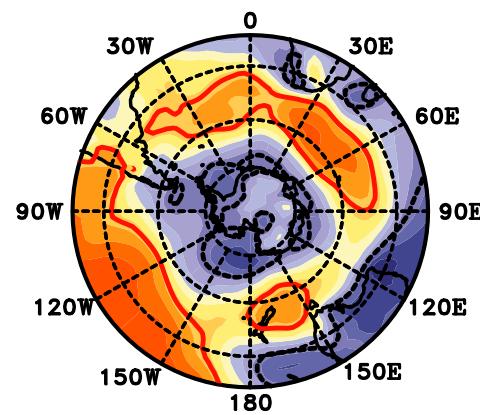

(e) 0 month (APR)

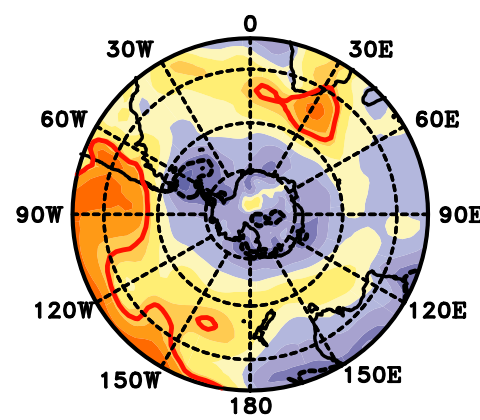

(h) +3 month (JUL)

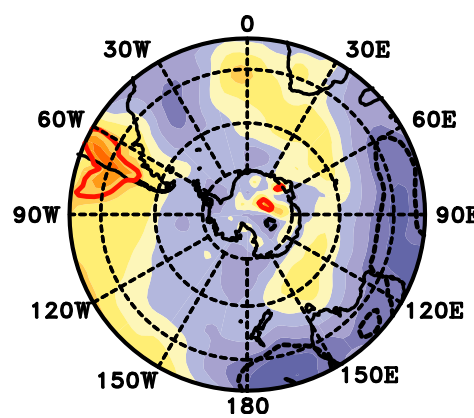

(c) -2 month (FEB)

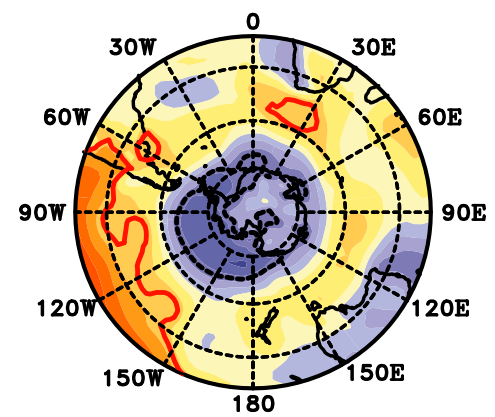

(f) +1 month (MAY)

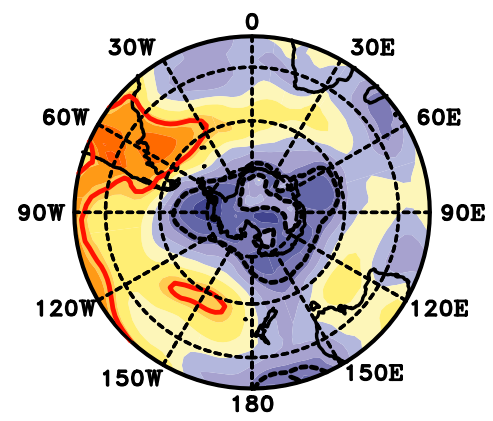

(i) +4 month (AUG)

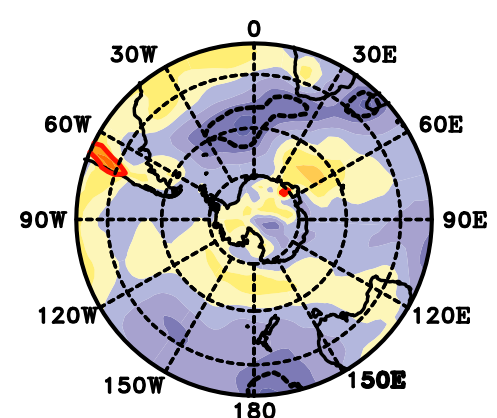

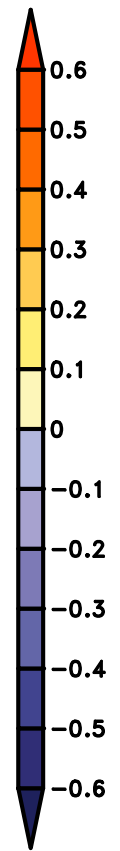

FIG. 5. Lead-lag correlation between the MAM SODI and sea level pressure for values of the lag between (top left) -4 and (bottom right) +4 months. The lag values decrease by one month in each case and the sea level pressure in (a) leads the SODI by 4 months and in (l) lags by 4 months.

similar analyses after removing the ENSO signal not change much (not shown).

\section{b. SST decomposition based on unary regression}

To explore the percentage of the $S(t-1)$ that can persist to the following time $t$ in the total $S(t-1)$, the $\mathrm{pr}_{1}$ is shown in Fig. 6a as the black solid line. It is found that more than $50 \%$ of the total DJF SSTA persists into the following MAM over most of the southern extratropics. In particular, the percentage can reach about $60 \%$ in the bands between $50^{\circ}-20^{\circ} \mathrm{S}$ and $70^{\circ}-65^{\circ} \mathrm{S}$. These results imply the strong persistence of the DJF extratropical SSTA. The results of $\mathrm{pr}_{2}$ are shown in Fig. $6 \mathrm{~b}$ as the black solid line. The persistent component derived from the DJF SST accounts for more than $50 \%$ in the total variability of southern extratropical MAM SST. In particular, the $\mathrm{pr}_{2}$ is relatively larger in the bands $70^{\circ}-$ $60^{\circ} \mathrm{S}$ and $40^{\circ}-25^{\circ} \mathrm{S}$. Combined with Fig. $6 \mathrm{a}$, it is found that a large part of DJF SST can persist to the MAM (Fig. 6a), and these persistent component indeed take a large part in total MAM SST (Fig. 6b).

Given that Ciasto and Thompson (2008) revealed that ENSO contributes to the persistence of SAM-related southern extratropical SSTA, similar analyses for $\mathrm{pr}_{1}$ and $\mathrm{pr}_{2}$ after removing the ENSO signals are shown in Figs. $6 \mathrm{a}$ and $6 \mathrm{~b}$ as the red dotted-dashed lines. For DJF 
SST, we remove the DJF ENSO signal. For MAM SST, we remove both the DJF and MAM ENSO signals. It can be seen that after removing the ENSO signal, the $\mathrm{pr}_{1}$ did not change much. In most regions, the changes are less than $5 \%$. The weakening of $\mathrm{pr}_{2}$ is about $10 \%$. This illustrates that ENSO indeed contributes to the DJF SST persistence after removing the ENSO signal. Although there is a weakening of persistence, the $\mathrm{pr}_{2}$ is still evident only decreasing about $10 \%$. In most latitudes, the $\mathrm{pr}_{2}$ is still larger than $50 \%$ after removing the ENSO signal.

According to Eq. (29), we can isolate the persistent component $S_{p}(t)$ from the total MAM SST. The correlation between the persistent component in MAM SST and the MAM SAM is shown in Fig. $6 \mathrm{c}$ as the black dotted-dashed line. Meanwhile, the correlation of total MAM SST with the MAM SAM is also shown in Fig. 6c as the black dashed line, which is same as the black dashed line in Fig. 2a $\left(a_{\mathrm{HP}}\right)$. It can be seen that the persistent component contributes to the direct correlation between the MAM SAM and total MAM SST $\left(a_{\mathrm{HP}}\right)$. In the region between $70^{\circ}$ and $51^{\circ} \mathrm{S}$ and between $43^{\circ}$ and $20^{\circ} \mathrm{S}$, the sign of these two correlations are the same implying the positive contribution of the persistent component. However, in the region between $51^{\circ}$ and $43^{\circ} \mathrm{S}$, the sign of these two correlations are opposite implying the negative contribution of the persistent component.

The reason for the negative contribution may be related to the fact that the signs of the correlation patterns between the SAM and SST in DJF and MAM are opposite in the regions where the negative contribution occurs (Fig. 2a). Regardless of whether the contribution is positive or negative, it is known from Fig. $6 c$ that the persistent component indeed contributes to the direct correlation between the MAM SAM and total MAM $\operatorname{SST}\left(a_{\mathrm{HP}}\right)$, and thus this direct correlation $\left(a_{\mathrm{HP}}\right)$ may not reflect the real linkage between the MAM SAM and MAM SST, because the total MAM SST contains a persistent component caused by the DJF SAM $\left[S_{P}(t)\right.$ as shown in Eq. (29)]. By a comparison between Fig. 6b and $6 c$, it is found that the contribution of the persistent component in Fig. $6 \mathrm{c}$ is larger in the regions where the $\mathrm{pr}_{2}$ is stronger as shown in Fig. $6 \mathrm{~b}\left(70^{\circ}-60^{\circ} \mathrm{S}\right.$ and $\left.40^{\circ}-25^{\circ} \mathrm{S}\right)$.

The red lines in Fig. $6 \mathrm{c}$ are similar to the black lines but after removing the ENSO signals. As previous studies have pointed out, ENSO contributes to the persistence of SAM-related southern extratropical SST (Ciasto and Thompson 2008). Removing the ENSO signal indeed impairs the contribution of the persistent contribution in the direct correlation between the MAM SAM and MAM SST. Generally, in regions with stronger decrease in the correlation between the MAM SAM
Percentage of Persistent Component in Total DJF SST (pr1)

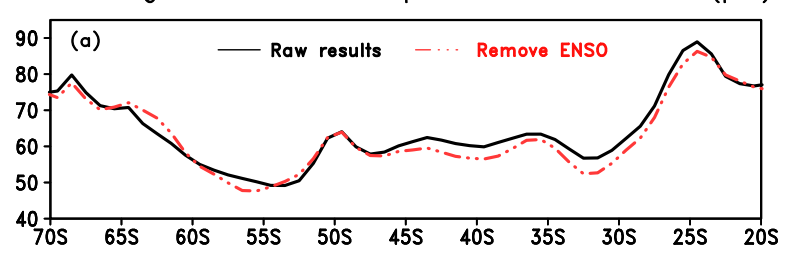

Percentage of Persistent Component in Total MAM SST (pr2)

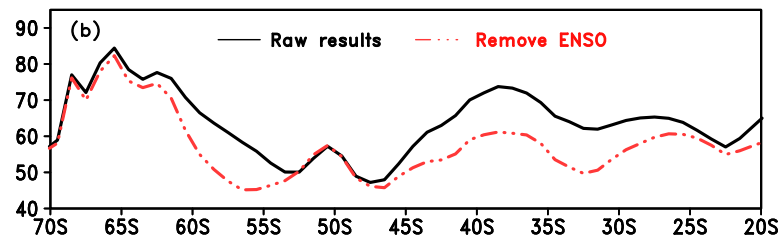

Corr. between MAM SAM and MAM Zonal-mean SST

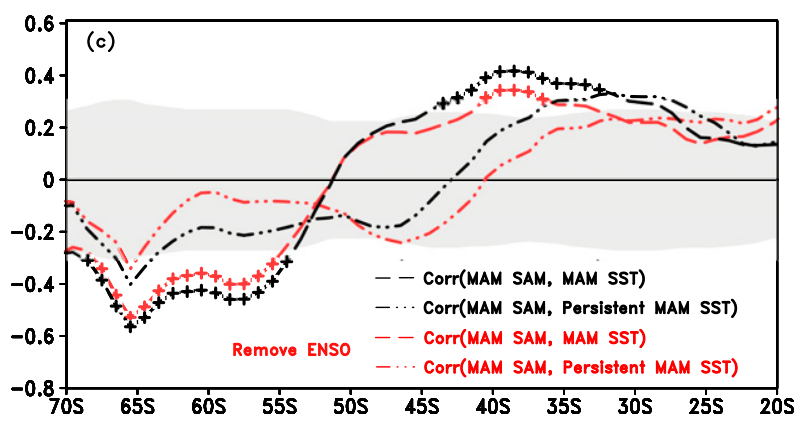

FIG. 6. (a) Percentage of persistent component in total DJF SST $\left(\mathrm{pr}_{1}\right)$. (b) Percentage of persistent component in total MAM SST $\left(\mathrm{pr}_{2}\right)$. (c) Correlation coefficients of the MAM SAM with MAM total SST (dashed) and the MAM persistent component SST (dotted-dashed). The black (red) lines in (a),(b) are the raw (after removing the ENSO signals) results. For DJF SST, we remove the DJF ENSO signal and for MAM SST, both the DJF and MAM ENSO signals. The plus symbols in (c) represent the $95 \%$ confidence level. The gray areas in (c) indicate that the significance is at the $<80 \%$ confidence level for the correlation between the DJF SAM and MAM SST.

and MAM persistent SST, the decrease in the correlation between the MAM SAM and MAM total SST is also stronger, indicating the importance of the persistent component in total MAM SST.

Through the above method in Eqs. (29)-(31), we can quantize the strength of the persistence by decomposing total MAM SST into the persistent component derived from DJF SST and the nonpersistent component independent of DJF SST. The results show that the persistent component indeed contributes to the direct correlation between the MAM SAM and MAM total SST $\left(a_{\mathrm{HP}}\right)$, implying that this direct correlation $\left(a_{\mathrm{HP}}\right)$ may not reflect the real linkage between the MAM SAM and MAM SST. However, the above method does not consider air-sea interaction and cannot distinguish the persistence of SST that is induced by a specific 
atmospheric factor (e.g., SAM). Therefore, the PSD is developed for distinguishing the persistent SST component related to a special atmospheric factor, here the SAM.

\section{c. Persistent signal decomposition}

The results based on the PSD are shown in Fig. 7. Under the framework of the PSD, $a_{\mathrm{AH}}$ [Eq. (18)] is used to reflect a more "accurate" homochronous linkage between the MAM SAM and MAM SST rather than the direct regression $a_{\mathrm{HP}}$ [Eq. (26)]. As noted in section 4, $a_{\mathrm{AH}}$ only contains the homochronous component, whereas $a_{\mathrm{HP}}$ contains both homochronous and persistent signals. To intuitively explore the difference between $a_{\mathrm{AH}}$ and $a_{\mathrm{HP}}$, they are shown together in Fig. 7a as the yellow solid and the black dashed line. It is clearly evident that $a_{\mathrm{AH}}$ is indeed different from $a_{\mathrm{HP}}$. There is $\left|a_{\mathrm{HP}}\right|>\left|a_{\mathrm{AH}}\right|$ in most regions, indicating that the persistent component makes a positive contribution to the direct correlation between the MAM SAM and MAM SST $\left(a_{\mathrm{HP}}\right)$. However, there is $\left|a_{\mathrm{HP}}\right|<\left|a_{\mathrm{AH}}\right|$ in regions between $50^{\circ}$ and $43^{\circ} \mathrm{S}$, indicating the negative contribution of the persistent component. The above results about the sign of the contribution of the persistent SST are consistent with Fig. $6 c$ (details in section 5b).

The $a_{P}$ [Eq. (25)] reflects the influence of the DJF SAM on MAM SST, and it is also shown in Fig. 7a as black solid line. Detecting the relative importance of the DJF and MAM SAM in modulating MAM SST, which is the focus of our work, can be regarded as a comparison between $a_{P}\left(C_{P}\right)$ and $a_{\mathrm{AH}}\left(C_{\mathrm{AH}}\right)$. It can be seen that there is $\left|a_{P}\right|>\left|a_{\mathrm{AH}}\right|$ at most latitudes, indicating that the influence of DJF SAM on southern extratropical MAM SST is stronger than that of the MAM SAM. To more clearly show this relative contribution, we investigate the corresponding explained variances, $C_{P}$ and $C_{\mathrm{AH}}$, which are shown in Fig. 7c. Similarly, there is $\left|C_{P}\right|>\left|C_{\mathrm{AH}}\right|$ at most latitudes, revealing that the influence of the DJF SAM on MAM SST is greater than that of the MAM SAM. This is especially the case in the high latitudes. The DJF SAM plays a more important role in driving MAM dipolelike SSTA in the southern extratropics.

To further explore the role of atmosphere persistence and SST persistence in the cross-seasonal influence, the $a_{\mathrm{SP} \_\mathrm{A}}$ and $a_{\mathrm{AP}}$ are shown in Fig. 7b as the green and blue lines. It is found in Fig. 7b that there is $\left|a_{\mathrm{SP} \_\mathrm{A}}\right|>\left|a_{\mathrm{AP}}\right|$ at most latitudes, implying that the cross-seasonal influence of the DJF SAM on MAM SST is mainly caused by the SST persistence $\left(a_{\mathrm{SP} \_\mathrm{A}}\right)$, with a smaller contribution from the persistence of SAM $\left(a_{\mathrm{AP}}\right)$. The $a_{\mathrm{AP}}$ is very weak at most latitudes, indicating that there is almost no evident relationship between DJF SAM and MAM SSTs
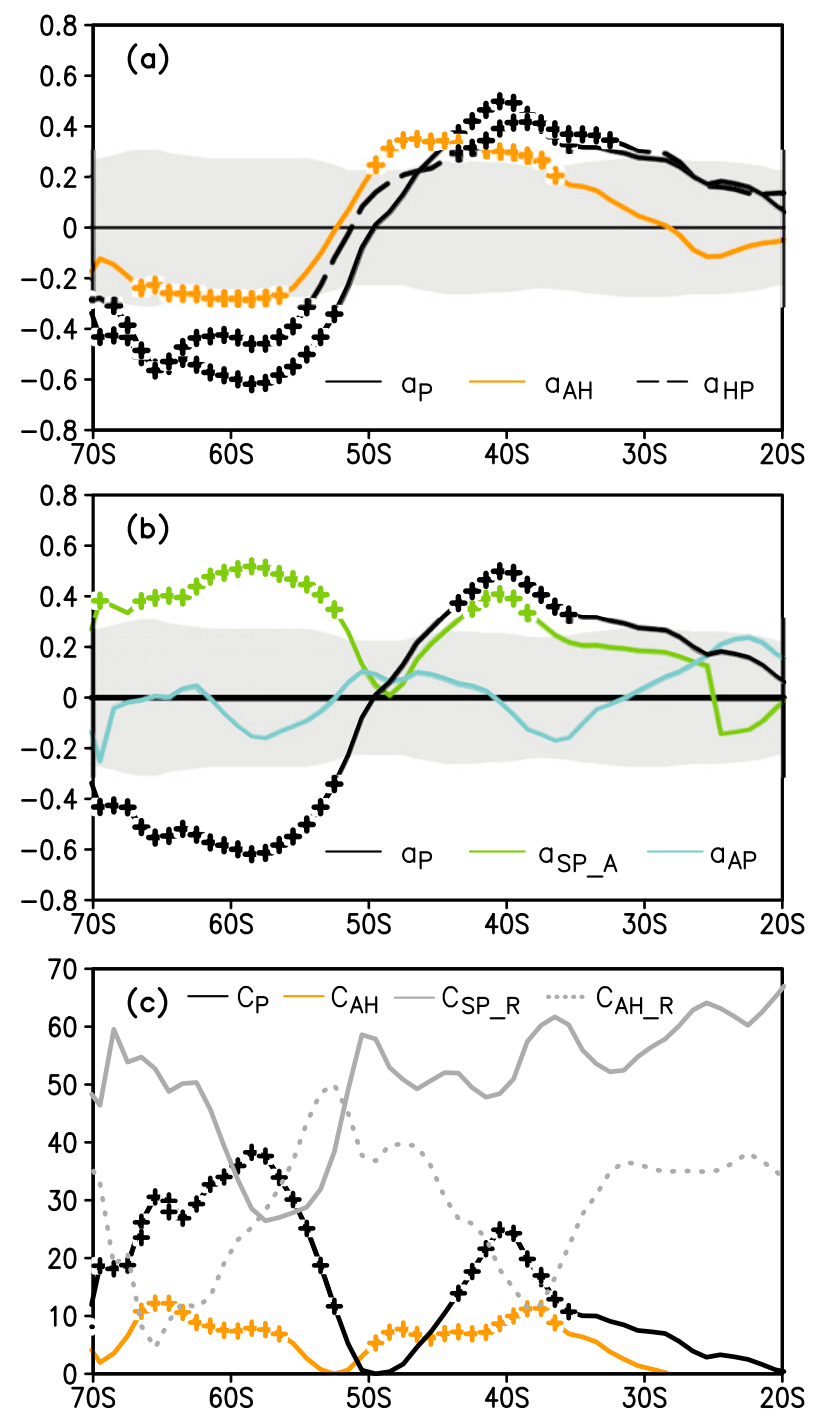

FIG. 7. The results from the PSD: (a) $a_{P}, a_{\mathrm{AH}}$, and $a_{\mathrm{HP}}$; (b) $a_{P}$, $a_{\mathrm{SP} \_\mathrm{A}}$, and $a_{\mathrm{AP}}$; and (c) $C_{P}, C_{\mathrm{AH}}, C_{\mathrm{SP} \_\mathrm{R}}$, and $C_{\mathrm{AH} \_\mathrm{R}}$. The plus symbols represent the $95 \%$ confidence level. The gray areas indicate that the significance is at the $<80 \%$ confidence level for the correlation between the DJF SAM and MAM SST.

if the SST persistence is removed. Thus, the ocean memory effect should be regarded as the crucial factor responsible for the cross-seasonal influence of the DJF SAM on MAM SST.

Furthermore, the $C_{\mathrm{SP}_{-} \mathrm{R}}$ and $C_{\mathrm{AH}_{-} \mathrm{R}}$ are shown in Fig. $7 \mathrm{c}$ as the gray solid line and the gray dotted line. As we mentioned before, the subscript $R$ in $C_{\mathrm{SP}_{-} \mathrm{R}}$ and $C_{\mathrm{AH} \_\mathrm{R}}$ means the residual parts, which are generally not associated with the atmospheric factor $A$ (here the SAM). Specifically, the $C_{\mathrm{SP}_{-} \mathrm{R}}$ is the component caused by persistence of SSTA, which is not associated with $A(t-1)$, and the $C_{\mathrm{AH} \_\mathrm{R}}$ represents the contribution from other contemporaneous influencing factors rather than 


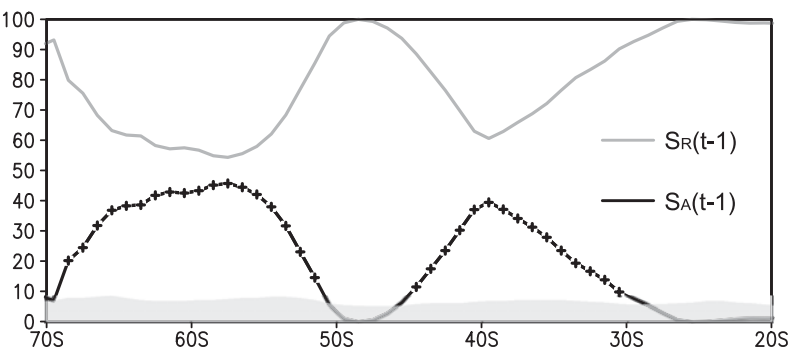

FIG. 8. Explained variances of the DJF SAM-related SSTA $\left[S_{A}(t-1)\right.$; black line $]$ and the residual component independent of the DJF SAM $\left[S_{R}(t-1)\right.$; gray line] in total DJF SST [S(t-1)]. The plus symbols represent the $95 \%$ confidence level. The gray area indicates that the significance is at the $<80 \%$ confidence level for the correlation between the $S_{A}(t-1)$ and $S(t-1)$.

$A(t)$. It can be seen in Fig. $7 \mathrm{c}$ that the $C_{\mathrm{SP}_{-} \mathrm{R}}$ is very strong in most regions in the southern extratropics, which is even stronger than the SAM-related terms $C_{P}$ and $C_{\mathrm{AH}}$ at most latitudes. In view of the high consistency between $C_{\mathrm{SP} \_\mathrm{R}}$ and $a_{\mathrm{SP} \_\mathrm{R}}$ (see Fig. $\mathrm{S} 1$ in the supplementary material), it is reliable that $a_{\mathrm{SP} \_\mathrm{R}}$ is also stronger than $a_{P}$ and $a_{\mathrm{AH}}$. The reason behind this is that the SAM is not the only factor that could influence southern extratropical SST, and the residual factors that could modulate southern extratropical SST cover a considerably wide range (e.g., oceanic eddies; Screen et al. 2009). For convenience, we treat the influence of the residual factors as a whole and show the explained variances of these residual factors [taken as $S_{R}(t-1)$ ] and that of the DJF SAM-related SSTA [taken as $S_{A}(t-1)$ ] in total DJF SST [taken as $S(t-1)$ ] in Fig. 8. It can be seen that DJF SAMrelated SSTA account for about $40 \%$ in the total variance of the DJF SST at around $40^{\circ}$ and $60^{\circ} \mathrm{S}$. In the regions at around $50^{\circ} \mathrm{S}$, the explained variance by the DJF SAM-related SSTA is nearly zero. The $S_{R}(t-1)$ includes the contributions from all other factors that could influence southern extratropical SST except for the SAM. The explained variance from $S_{R}(t-1)$ is greater than that from the SAM-related $S_{A}(t-1)$. Therefore, it is reasonable that the $C_{\mathrm{SP}_{\mathrm{R}} \mathrm{R}}$ is stronger than the contribution from the SAM-related terms $C_{P}$ and $C_{\mathrm{AH}}$.

Finally, Fig. 9 is similar to Fig. 7, but only after removing the ENSO signal. Comparing Figs. 7a and 9a and Figs. $7 \mathrm{~b}$ and $9 \mathrm{~b}$, it is found that removing the ENSO signal almost has no effect on $a_{\mathrm{AH}}$ and $a_{\mathrm{AP}}$. As reveal by Ciasto and Thompson (2008), ENSO contributes to the persistence of the SAM-related southern extratropical SST. In the PSD, the $a_{\mathrm{SP} \_\mathrm{A}}$ is a reflection of the role of SST persistence. It can be seen from Fig. $9 \mathrm{~b}$ that removing the ENSO signal indeed impairs the $a_{\mathrm{SP} \_\mathrm{A}}$. The decrease of $a_{\mathrm{SP} \_\mathrm{A}}$ is stronger in the middle latitudes than that in the high latitudes, indicating that the perturbation of ENSO on the persistence of SAM-related SSTA is stronger
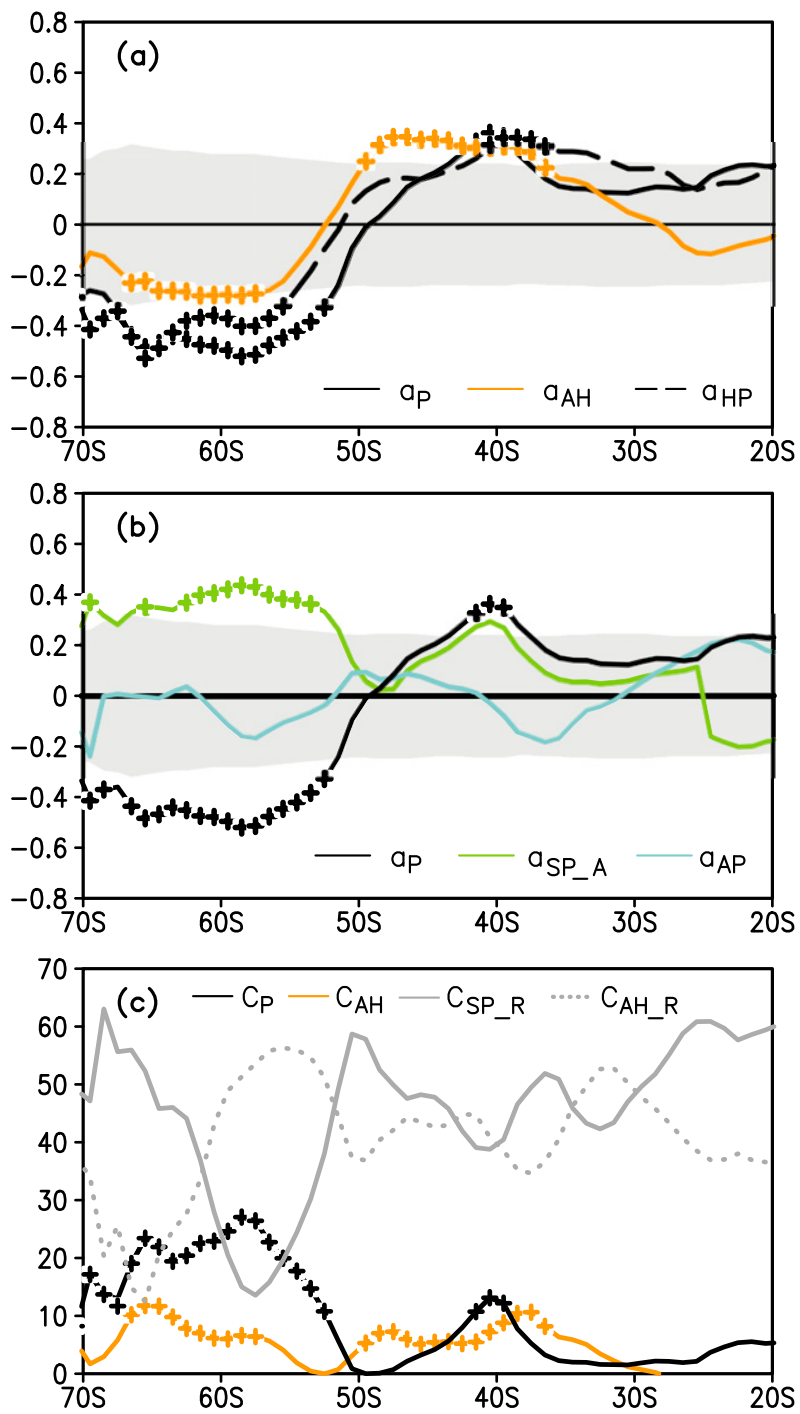

FIG. 9. As in Fig. 7, but after removing the ENSO signals. For DJF SST, we remove the DJF ENSO signal and for MAM SST, both the DJF and MAM ENSO signals.

in the middle latitudes than that in the high latitudes. Although ENSO contributes to the persistence of the SAM-related SSTA, it is evident from Fig. 9c that there is still $\left|C_{P}\right|>\left|C_{\mathrm{AH}}\right|$ at most latitudes, especially in the high latitudes. These results illustrate again that the influence of the DJF SAM on MAM SOD is greater than that of the MAM SAM.

\section{Conclusions and discussion}

In this work, we propose a new calculating process under the framework of extratropical air-sea interactions for exploring the relative importance of the DJF and MAM SAM in influencing the MAM southern 
extratropical SST. It is found that the DJF SAM plays a more important role than the MAM SAM in modulating the large-scale dipolelike MAM SSTA in the southern extratropics, implying that the DJF SAM and associated SSTA can be regarded as effective predictors for the following season's climate because the MAM SSTA caused by the DJF SAM would not be largely perturbed.

Note that this conclusion concentrates on the largescale zonal-mean southern extratropical SSTA. As previously mentioned, there is zonal asymmetry of the correlation coefficients between the SAM and SST, and the MAM SAM may be dominant in influencing spring SST in some specific locations. In addition, the seasonal dependence of the persistence of large-scale SSTA is well established, and is usually linked with the depth of the ocean mixed layer (Screen et al. 2009; Ciasto et al. 2011). Considering the seasonal variation in SST persistence, although the preceding SAM is more important than the contemporaneous SAM in influencing MAM SST, the relative importance of the preceding and contemporaneous SAM in modulating SST in other seasons should be investigated further.

Compared with traditional SST decomposition, the new calculating process proposed here, the PSD, takes the extratropical air-sea interactions into account and provides a more detailed decomposition of total SST. On the one hand, the PSD can detect the SST persistence associated with one specific atmospheric factor. The PSD detects persistent SST that is closely related to the dominant atmospheric signal $\left(C_{\mathrm{SP}_{-} \mathrm{A}}\right)$, instead of treating $C_{\mathrm{SP}_{-} \mathrm{A}}$ and $C_{\mathrm{SP}_{-} \mathrm{R}}$ together. In fact, it is found that $C_{\mathrm{SP}_{-} \mathrm{R}}\left(a_{\mathrm{SP}_{-} \mathrm{R}}\right)$ is a very large term, which reflects the strong persistence of SSTA that is not related to the SAM. This is because other factors apart from the SAM could also modulate southern extratropical SST. The $C_{\mathrm{SP} \_\mathrm{R}}\left(a_{\mathrm{SP} \_\mathrm{R}}\right)$ reflects a combination of the SSTA persistence caused by all these residual factors, which cover a considerably wide range (e.g., oceanic eddies; Screen et al. 2009). On the other hand, the PSD distinguishes the persistence of the dominant atmospheric signal $\left(C_{\mathrm{AP}}\right)$ from that of SST $\left(C_{\mathrm{SP}_{-} \mathrm{A}}\right)$. Our results show that the cross-seasonal influence of the DJF SAM on spring SST is mainly caused by the persistence of SST $\left(C_{\mathrm{SP} \_\mathrm{A}}\right)$. The persistence of the SAM $\left(C_{\mathrm{AP}}\right)$ plays a limited role.

The detection of the relative importance of the preceding and contemporaneous atmospheric signal in driving SSTA has more general applicability. It can contribute to our understanding of air-sea interactions and help to obtain better SST-based statistical predictions, because the persistent component originating in the preceding season has the potential to be used as a predictor. Detecting persistent and nonpersistent SSTA originating in different seasons is a general question in the "ocean-atmosphere coupled bridge" (Zheng and Li 2012; Li et al. 2013a; Zheng et al. 2013), in which the ocean memorizes the signal of the large-scale atmospheric circulation as SSTA, which persists to the following season, alters the atmospheric circulation, and finally influences local and remote climate. Detecting persistent and nonpersistent SSTA originating in different seasons is also a general question in the "seasonal footprinting mechanism" (Vimont et al. 2001, 2003; Alexander et al. 2010), which can be summarized as follows. During the winter season, intrinsic atmospheric variability (North Pacific Oscillation) imparts an SST footprint onto the ocean. This SST footprint persists into the late spring and summer seasons, which in turn, forces a pattern of atmospheric circulation anomalies (e.g., zonal wind stress anomalies along the equator) and finally produces an ENSO-like pattern of variability. In the oceanatmosphere coupled bridge and seasonal footprinting mechanism, the persistence of SST provides an important source of predictability, and thus it is necessary to explore the relative importance of the atmospheric signal in different seasons in influencing the SSTA.

Except for the influence of DJF SAM on southern China MAM precipitation, other cross-seasonal teleconnection that are based on the ocean-atmosphere coupled bridge can be found in the influence of the MAM NAO on East Asian summer monsoon (Wu et al. 2009b) and in the connection between the June-August (JJA) NAO and September-November (SON) precipitation over central China (Xu et al. 2013). The North Atlantic SST has important implications for statistical seasonal prediction in many regions of the world (Rodwell et al. 1999; Pan 2007; Wu et al. 2009b, 2012; Li et al. 2013b; Zuo et al. 2013). To obtain better statistical predictions based on the North Atlantic SST, it is helpful to conduct signal decomposition to explicitly detect the origination of the SSTA. The PSD has the potential to be employed in the North Atlantic and other extratropical oceans.

There are also some limitations to the PSD. Note that the PSD only considers two consecutive seasons when carrying out SST decomposition (Fig. 4). Actually, $S(t)$ may also contain SSTA associated with $A(t-2)$. When carrying out the decomposition for $S(t)$ in the present study, given that influence of the SON SAM on MAM SOD is relatively weak (not shown), we did not single out the role of the SON SAM, and its influence is actually included in $C_{\mathrm{SP}_{-} \mathrm{R}}$. In addition, the schematic of PSD in Fig. 1 is a simplification of the complex extratropical air-sea interaction system with persistent features. The PSD only considers the one-way influence of the atmospheric signal on SST. This assumption is regarded as relatively reliable in the extratropics for the 
large-scale SST anomaly pattern, but is not appropriate in the tropics where the ocean has strong feedback effects on the atmospheric circulation. Some recent meaningful researches have paid attention to the feedback of SSTA pattern on the atmospheric mode in the extratropics (Sen Gupta and England 2007). Although this feedback is generally weaker than the influence of the atmospheric mode on SST in the extratropics, the feedback of SAM-related SSTA on SAM contributes to the persistence of the SAM (Sen Gupta and England 2007). Further analyses are needed to enrich the framework of the PSD and take into account the feedback of the SSTA on the atmospheric signal.

Acknowledgments. This work was jointly supported by the 973 Program (2013CB430200) and the NSFC Project (41405086). We are grateful to Dr. Sen Zhao in LASG/IAP for comments on this work. The comments from Dr. Judith Perlwitz and the anonymous reviewers led to a significant improvement of this paper.

\section{REFERENCES}

Alexander, M. A., D. J. Vimont, P. Chang, and J. D. Scott, 2010: The impact of extratropical atmospheric variability on ENSO: Testing the seasonal footprinting mechanism using coupled model experiments. J. Climate, 23, 2885-2901, doi:10.1175/ 2010JCLI3205.1.

Barnston, A. G., and R. E. Livezey, 1987: Classification, seasonality and persistence of low-frequency atmospheric circulation patterns. Mon. Wea. Rev., 115, 1083-1126, doi:10.1175/ 1520-0493(1987)115<1083:CSAPOL>2.0.CO;2.

Cai, W. J., and I. G. Watterson, 2002: Modes of interannual variability of the Southern Hemisphere circulation simulated by the CSIRO climate model. J. Climate, 15, 1159-1174, doi:10.1175/ 1520-0442(2002)015<1159:MOIVOT>2.0.CO;2.

Chen, W., 1982: Fluctuations in Northern Hemisphere $700 \mathrm{mb}$ height field associated with the Southern Oscillation. Mon. Wea. Rev., 110, 808-823, doi:10.1175/1520-0493(1982)110<0808: FINHMH $>2.0 . \mathrm{CO} ; 2$.

Ciasto, L. M., and D. W. J. Thompson, 2008: Observations of largescale ocean-atmosphere interaction in the Southern Hemisphere. J. Climate, 21, 1244-1259, doi:10.1175/2007JCLI1809.1.

_- M. A. Alexander, C. Deser, and M. H. England, 2011: On the persistence of cold season SST anomalies associated with the annular modes. J. Climate, 24, 2500-2515, doi:10.1175/ 2010JCLI3535.1.

— , G. R. Simpkins, and M. H. England, 2015: Teleconnections between tropical Pacific SST anomalies and extratropical Southern Hemisphere climate. J. Climate, 28, 56-65, doi:10.1175/ JCLI-D-14-00438.1.

Davis, R. E., 1976: Predictability of sea surface temperature and sea level pressure anomalies over the North Pacific Ocean. J. Phys. Oceanogr., 6, 249-266, doi:10.1175/1520-0485(1976)006<0249: POSSTA $>2.0 . \mathrm{CO} ; 2$.

Deser, C., M. A. Alexander, and M. Timlin, 2003: Understanding the persistence of sea surface temperature anomalies in midlatitudes. J. Climate, 16, 57-72, doi:10.1175/1520-0442(2003)016<0057: UTPOSS $>2.0 . \mathrm{CO} ; 2$. $\longrightarrow,-$, S. P. Xie, and A. S. Phillips, 2010: Sea surface temperature variability: Patterns and mechanisms. Annu. Rev. Mar. Sci., 2, 115-143, doi:10.1146/annurev-marine-120408-151453.

Ding, Q. H., B. Wang, J. M. Wallace, and G. Branstator, 2011: Tropical-extratropical teleconnections in boreal summer: Observed interannual variability. J. Climate, 24, 1878-1896, doi:10.1175/2011JCLI3621.1.

_ E. Steig, D. Battisti, and J. M. Wallace, 2012: Influence of the tropics on the southern annular mode. J. Climate, 25, 63306348, doi:10.1175/JCLI-D-11-00523.1.

Ding, R. Q., and J. P. Li, 2011: Winter persistence barrier of sea surface temperature in the northern tropical Atlantic associated with ENSO. J. Climate, 24, 2285-2299, doi:10.1175/ 2011JCLI3784.1.

_- and —_, 2012: Influences of ENSO teleconnection on the persistence of sea surface temperature in the tropical Indian Ocean. J. Climate, 25, 8177-8195, doi:10.1175/ JCLI-D-11-00739.1.

Feng, J., J. P. Li, and Y. Li, 2010: Is there a relationship between the SAM and southwest Western Australian winter rainfall? J. Climate, 23, 6082-6089, doi:10.1175/2010JCLI3667.1.

$\longrightarrow,-$, and H. L. Xu, 2013: Increased summer rainfall in northwest Australia linked to southern Indian Ocean climate variability. J. Geophys. Res. Atmos., 118, 467-480, doi:10.1029/ 2012JD018323.

Frankignoul, C., and K. Hasselmann, 1977: Stochastic climate models. Part 2. Application to sea-surface temperature variability and thermocline variability. Tellus, 29A, 289-305, doi:10.1111/j.2153-3490.1977.tb00740.x.

Gong, D. Y., and S. W. Wang, 1999: Definition of Antarctic Oscillation index. Geophys. Res. Lett., 26, 459-462, doi:10.1029/ 1999GL900003.

Gong, T. T., S. B. Feldstein, and D. H. Luo, 2010: The impact of ENSO on wave breaking and southern annular mode events. J. Atmos. Sci., 67, 2854-2870, doi:10.1175/2010JAS3311.1.

Karoly, D. J., 1989: Southern Hemisphere circulation features associated with El Niño-Southern Oscillation events. J. Climate, 2, 1239-1252, doi:10.1175/1520-0442(1989)002<1239: SHCFAW $>2.0 . \mathrm{CO} ; 2$.

Lefebvre, W., H. Goosse, R. Timmermann, and T. Fichefet, 2004: Influence of the Southern Annular Mode on the sea iceocean system. J. Geophys. Res., 109, C09005, doi:10.1029/ 2004JC002403.

Li, J. P., and J. X. L. Wang, 2003: A modified zonal index and its physical sense. Geophys. Res. Lett., 30, 1632, doi:10.1029/ 2003GL017441.

_ , and Coauthors, 2013a: Progress in air-land-sea interactions in Asia and their role in global and Asian climate change (in Chinese). Chin. J. Atmos. Sci., 37, 518-538.

- C. Sun, and F. F. Jin, 2013b: NAO implicated as a predictor of Northern Hemisphere mean temperature multidecadal variability. Geophys. Res. Lett., 40, 5497-5502, doi:10.1002/ 2013 GL057877.

Li, X. F., and J. P. Li, 2012: Analysis of the quasi-geostrophic adjustment process of the Southern Hemisphere annular mode (in Chinese). Chin. J. Atmos. Sci., 36, 755-768.

Limpasuvan, V., and D. L. Hartmann, 1999: Eddies and the annular modes of climate variability. Geophys. Res. Lett., 26, 31333136, doi:10.1029/1999GL010478.

Namias, J., X. Yuan, and D. R. Cayan, 1988: Persistence of North Pacific sea surface temperature and atmospheric flow patterns. J. Climate, 1, 682-703, doi:10.1175/1520-0442(1988)001<0682: PONPSS $>2.0 . \mathrm{CO} ; 2$. 
Nan, S. L., and J. P. Li, 2003: The relationship between the summer precipitation in the Yangtze River valley and the boreal spring Southern Hemisphere annular mode. Geophys. Res. Lett., 30, 2266, doi:10.1029/2003GL018381.

,$- \ldots$, X. J. Yuan, and P. Zhao, 2009: Boreal spring Southern Hemisphere Annular Mode, Indian Ocean sea surface temperature, and East Asian summer monsoon. J. Geophys. Res., 114, D02103, doi:10.1029/2008JD010045.

Pan, L., 2005: Observed positive feedback between the NAO and the North Atlantic SSTA tripole. Geophys. Res. Lett., 32, L06707, doi:10.1029/2005GL022427.

_ 2007: Synoptic eddy feedback and air-sea interaction in the North Atlantic region. Climate Dyn., 29, 647-659, doi:10.1007/ s00382-007-0256-7.

Rodwell, M. J., D. P. Rodwell, and C. K. Folland, 1999: Oceanic forcing of the wintertime North Atlantic Oscillation and European climate. Nature, 398, 320-323, doi:10.1038/18648.

Screen, J. A., N. P. Gillett, D. P. Stevens, G. J. Marshall, and H. K. Roscoe, 2009: The role of eddies in the Southern Ocean temperature response to the southern annular mode. J. Climate, 22, 806-818, doi:10.1175/2008JCLI2416.1.

Seager, R., N. Harnik, Y. Kushnir, W. Robinson, and J. Miller, 2003: Mechanisms of hemispherically symmetric climate variability. J. Climate, 16, 2960-2978, doi:10.1175/1520-0442(2003)016<2960: MOHSCV $>2.0 . \mathrm{CO} ; 2$.

Sen Gupta, A., and M. H. England, 2006: Coupled oceanatmosphere-ice response to variations in the southern annular mode. J. Climate, 19, 4457-4486, doi:10.1175/JCLI3843.1.

- , and 2007: Coupled ocean-atmosphere feedback in the southern annular mode. J. Climate, 20, 3677-3692, doi:10.1175/ JCLI4200.1.

Simpkins, G. R., S. McGregor, A. S. Taschetto, L. M. Ciasto, and M. H. England, 2014: Tropical connections to climatic change in the extratropical Southern Hemisphere: The role of Atlantic SST trends. J. Climate, 27, 4923-4936, doi:10.1175/ JCLI-D-13-00615.1.

Thompson, D. W. J., and J. M. Wallace, 2000: Annular modes in the extratropical circulation. Part I: Month-to-month variability. J. Climate, 13, 1000-1016, doi:10.1175/1520-0442(2000)013<1000: AMITEC $>2.0 . \mathrm{CO} ; 2$.

,-- , and G. C. Hegerl, 2000: Annular modes in the extratropical circulation. Part II: Trends. J. Climate, 13, 1018-1036, doi:10.1175/1520-0442(2000)013<1018:AMITEC > 2.0.CO;2.

— S. Solomon, P. J. Kushner, M. H. England, K. M. Grise, and D. J. Karoly, 2011: Signatures of the Antarctic ozone hole in Southern Hemisphere surface climate change. Nat. Geosci., 4, 741-749, doi:10.1038/ngeo1296.

Tokinaga, H., S.-P. Xie, C. Deser, Y. Kosaka, and Y. M. Okumura, 2012: Slowdown of the Walker circulation driven by tropical
Indo-Pacific warming. Nature, 491, 439-443, doi:10.1038/ nature11576.

Vimont, D. J., D. S. Battisti, and A. C. Hirst, 2001: Footprinting: A seasonal connection between the tropics and mid-latitudes. Geophys. Res. Lett., 28, 3923-3926, doi:10.1029/2001GL013435.

,-- , and _ 2003: The seasonal footprinting mechanism in the CSIRO general circulation models. J. Climate, 16, 2653-2667, doi:10.1175/1520-0442(2003)016<2653:TSFMIT >2.0.CO;2.

Wang, B., R. Wu, and X. Fu, 2000: Pacific-East Asia teleconnection: How does ENSO affect East Asian climate? J. Climate, 13, 1517-1536, doi:10.1175/1520-0442(2000)013<1517: PEATHD $>2.0 . \mathrm{CO} ; 2$.

Watanabe, M., and M. Kimoto, 2000: On the persistence of decadal SST anomalies in the North Atlantic. J. Climate 13, 3017-3028, doi:10.1175/1520-0442(2000)013<3017: OTPODS $>2.0 . \mathrm{CO} ; 2$.

Watterson, I. G., 2000: Southern midlatitude zonal wind vacillation and its interaction with the ocean in GCM simulations. J. Climate, 13, 562-578, doi:10.1175/1520-0442(2000)013<0562: SMZWVA $>2.0 . \mathrm{CO} ; 2$.

Wu, Z. W., J. P. Li, B. Wang, and X. H. Liu, 2009a: Can the Southern Hemisphere annular mode affect China winter monsoon? J. Geophys. Res., 114, D11107, doi:10.1029/2008JD011501.

_, B. Wang, J. P. Li, and F. Jin, 2009b: An empirical seasonal prediction model of the East Asian summer monsoon using ENSO and NAO. J. Geophys. Res., 114, D18120, doi:10.1029/ 2009JD011733.

_ J. Ji, Z. Jiang, J. He, and X. Zhu, 2012: Possible effects of the North Atlantic Oscillation on the strengthening relationship between the East Asian summer monsoon and ENSO. Int. J. Climatol., 32, 794-800, doi:10.1002/joc.2309.

Xu, H., J. Feng, and C. Sun, 2013: Impact of preceding summer North Atlantic Oscillation on early autumn precipitation over central China. Atmos. Oceanic Sci. Lett., 6, 417-422.

Zheng, F., and J. P. Li, 2012: Impact of preceding boreal winter southern hemisphere annular mode on spring precipitation over south China and related mechanism (in Chinese). Chin. J. Geophys., 55, 3542-3557.

,-- , R. Clark, and H. Nnamchi, 2013: Simulation and projection of the Southern Hemisphere annular mode in CMIP5 models. J. Climate, 26, 9860-9879, doi:10.1175/JCLI-D-13-00204.1.

Zhou, T. J., and R. C. Yu, 2004: Sea-surface temperature induced variability of the Southern Annular Mode in an atmospheric general circulation model. Geophys. Res. Lett., 31, L24206, doi:10.1029/2004GL021473.

Zuo, J. Q., W. J. Li, C. H. Sun, L. Xu, and H. L. Ren, 2013: Impact of the North Atlantic sea surface temperature tripole on the East Asian summer monsoon. Adv. Atmos. Sci., 30, 11731186, doi:10.1007/s00376-012-2125-5. 